\title{
Sobre la noción de contrato en las Instituciones de Gayo*
}

\section{IAdolfo Wegmann Stockebrand**}

Resumen. El presente artículo aborda la noción de contrato contenida en las Instituciones de Gayo en el sentido de acto lícito generador de obligaciones, contrapuesto únicamente al delito, y su aplicación en fragmentos de la jurisprudencia tardo-clásica. De esa manera, pretendemos demostrar que la dicotomía contractus-delictum, lejos de constituir una peculiaridad del manual gayano, representa una doctrina contractual entre otras que desarrolló la jurisprudencia romana, que nada tiene que ver con la idea de contrato del derecho moderno, fundada en el acuerdo de voluntades de las partes.

Palabras clave: contractus, obligatio ex contractu, Instituciones de Gayo.

\section{On the Idea of Contract in the Institutions of Gaius}

Авstract. This article examines the notion of contract in the Institutions of Gaius as a lawful act with legal obligations, opposed only to ordinary civil trans-

Este artículo forma parte del proyecto Fondecyt Regular n. ${ }^{\circ}$ i I 703 I 6, "The Systematisation of Roman Law", del cual el autor es coinvestigador.

Fecha de recepción: I 7 de julio de 2017 . Fecha de aceptación: 8 de enero de 2018.

Para citar el artículo: Wegmann Stockebrand, A., "Sobre la noción de contrato en las Instituciones de Gayo", Revista de Derecho Privado, Universidad Externado de Colombia, n. ${ }^{\circ} 34$, enero-junio de 20I8, I9-49. DoI: https://doi.org/IO.I860I/or 234366.n34.02

** Doctor en Derecho, Universidad de Heidelberg, Alemania. Profesor de Derecho Privado (Derecho Romano y Derecho Civil), Facultad de Derecho de la Pontificia Universidad Católica de Chile, Santiago, Chile. Contacto: aawegman@uc.cl 
gressions (torts). For that purpose, the study draws its attention on fragments of late-Classic jurisprudence. In this way, I intend to show that the dichotomy contractus-delictum does not constitute a peculiarity of Gaius' text, but it represents one of the many doctrines on contracts developed by Roman jurisprudence. Such a notion would not be related to the idea of contract in modern law, which is grounded on the parties' agreement.

Keywords: Contractus, obligatio ex contractu, Institutions of Gaius.

Sumario. Introducción. i. Summa divisio obligationum y noción de contractus. A. La summa divisio de Gai. 3,88. B. La noción "gayana” de contractus en otros pasajes de las Institutiones. C. La noción "gayana” de contractus en otras fuentes de la jurisprudencia clásica. D. ¿Una clasificación incompleta de las causae obligationum? Conclusiones y perspectivas. Bibliografía.

\section{Introducción}

La clasificación de las instituciones jurídicas romanas en categorías es, principalmente, un producto de la literatura didáctica clásica y posclásica ${ }^{\mathrm{I}}$, con claras influencias del pensamiento filosófico griego, en particular de la dialéctica ${ }^{2}$, y la

I Sobre la literatura jurídica didáctica en general y sobre Gayo en especial, véase por todos, en español, Guzmán Brito, A., "Dialéctica, casuística y sistemática en la jurisprudencia romana”, Revista de Estudios Histórico-furídicos, t. v, I980, I 7 ss.; íD., "El carácter dialéctico del sistema de las Institutiones de Gayo", en Carvajal (ed.), Estudios de derecho romano en homenaje al Prof. Dr. D. Francisco Samper, Santiago, Librotecnia, 2007, 427 ss.; íD., "La tripartición del 'omne ius' en 'personae, res, actiones' y la doctrina retórica de las 'circumstantiae", en Fides Humanitas Ivs. Studii in onore di Luigi Labruna, Iv, Napoli, Edizioni Scientifiche Italiane, 2007, 2429 ss. Fundamental sobre la -controvertida- división de las obras jurídicas romanas en géneros literarios (Wertgattungen) y la consiguiente idea de un género de literatura didáctica ("isagogische Literatur") Schulz, F., Geschichte der römischen Rechtswissenschaft, Weimar, Hermann Böhlaus Nachfolger, I96 I, esp. I86 ss. para las obras didácticas de época clásica; más recientemente Liebs, D., "Jurisprudenz", en Sallmann (ed.), Die Literatur des Umbruchs. Von der römischen zur christlichen Literatur. I I 7 bis 284 n. Chr., en Herzog/Schmidt (eds.), Handbuch der lateinischen Literatur der Antike Iv, München, C.H. Beck, I 997,83 ss.

2 Sobre las raíces griegas de la construcción de categorías jurídicas en el derecho romano véase, por todos, Wieacker, F., "Griechische Wurzeln des Institutionensystems", en Zeitschrift der Savigny Stiftung für Rechtsgeschichte, romanistische Abteilung, t. Lxx, I953, 93 ss.; íD., "Über das Verhältnis der römischen Fachjurisprudenz zur griechisch-hellenistischen Theorie", en Iura: Rivista internazionale di diritto romano e antico, t. xx, I969, 448 ss.; íD., "Grundlagen der Systembildung in der römischen Jurisprudenz", en Buccellato (ed.), La sistematica giuridica. Storia, teoria e problemi attuali, Roma, Istituto della Enciclopedia Italiana, I99 I, 63 ss. Con una orientación más filosófica La Pira, G., "La genesi del sistema nella giurisprudenza romana. L'arte sistematrice", en Bullettino dell'Istituto di Diritto Romano 'Vittorio Scialoja', t. XLII, I934, 336 ss.; ÍD., "La genesi del sistema nella giurisprudenza romana. Il metodo", en Studia et Documenta Historiae et Iuris, t. I, I935, 3 I9 ss.; íD., "La genesi del sistema nella giurisprudenza romana. Il concetto di scienza e gli strumenti della costruzione scientifica", en Bullettino dell'Istituto di 
consiguiente estructuración de las materias en género (genus) y especie (species) 3 . Con todo, el influjo de la dialéctica griega se extiende bastante más allá de los

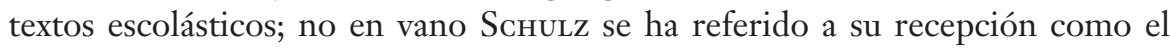
"fuego de Prometeo" de la ciencia jurídica romana 4 , un encuentro de dos mundos que se puede retrotraer en el tiempo al menos hasta el último siglo de la República con Q. Mucio Escévola, el primer jurisconsulto que habría intentado ordenar "sistemáticamente" -así, entre comillas-5 el derecho privado romano

Diritto Romano 'Vittorio Scialoja', t. xLIv, I936, I 3 I ss. En detalle sobre construcciones sistemáticas para fines didácticos en la antigüedad clásica, Fuhrmann, M., Das systematische Lebrbuch. Ein Beitrag zur Geschichte der Wissenschaften in der Antike, Göttingen, Vandenhoeck \& Ruprecht, I960; VILley, M., Recherches sur la litterature didactique du droit romain. A propos d'un texte de Ciceron, De oratore I-I 88 à I 90 , Paris, Domat-Montchrestien, I945.

3 Sobre esta estructura dialéctica en derecho romano son fundamentales los estudios de Talamanca, M., "Lo schema 'genus-species' nelle sistematiche dei giuristi romani", en La filosofia greca e il diritto romano (colloquio italo-francese) II, Roma, Accademia Nazionale dei Lincei, I977, 3 ss.; y Nörr, D., Divisio und partitio. Bemerkungen zur römischen Rechtsquellenlehre und zur antiken Wissenschaftstheorie, Berlin, Schweitzer, I972. Para las Instituciones de Gayo en particular véase Orestano, R., "Obligationes e dialettica”, en Droits de l'antiquité et sociologie juridique. Mélanges Henri Lévy-Brubl, Paris, Sirey, i 959, 445 ss.; Martini, R., "Genus e species nel linguaggio gaiano", en Synteleia Vincenzo Arangio-Ruiz I, Napoli, Jovene, I964, 462 ss.; íD., "La sistematica dei giuristi romani", en Index: Quaderni camerti di studi romanistici, International survey of Roman law, t. xxxiv, 2006, 87 ss.; así como los ya citados trabajos de Guzmán Brito, Dialéctica, cit., I 7 ss.; ÍD., El carácter dialéctico, cit., 427 ss.

4 Schulz, Geschichte, cit., 82: "für die römische furisprudenz war die Dialektik wirklich das Feuer des Prometheus".

5 La moderna idea de sistema no es susceptible de ser aplicada sin más a la experiencia jurídica romana, problema metodológico no siempre fácil de comprender para el estudioso del derecho vigente. Sobre esta cuestión, que no puede ser tratada en detalle en esta sede, véase la acertada apreciación de Cuena Boy, F., Sistema jurídico y derecho romano. La idea de sistema jurídico y su proyección en la experiencia jurídica romana, Santander, Universidad de Cantabria, i998, i6: "Sin llegar a la necesidad de una comprobación concreta, e incluso antes de toda precisión sobre su configuración y su concepto, la mayoría de los juristas parece aceptar de buena gana la existencia real del sistema jurídico. El punto de partida es la convicción de que el sistema -al que en un plano primario y puramente intuitivo se equipara con la noción genérica de 'orden'es inherente al concepto mismo de derecho y que, por tanto, todo derecho históricamente determinado ha de tener su sistema propio". El fenómeno descrito por el autor citado se debe en gran parte a la "deformación" provocada por la tradición romanística y, muy en particular, por la sistemática de la ciencia pandectística del siglo xix. En este sentido, p. ej., Bretone, M., Tecniche e ideologie dei giuristi romani, 2. ${ }^{\text {a }}$ ed., Napoli, Edizioni Scientifiche Italiane, I982, Ix; VAcca, L., Metodo casistico e sistema prudenziale, Padova, Cedam, 2006, 30. En general, sobre el problema de los así llamados "anteojos pandectistas" (pandektistiche Brille) deformantes de la experiencia jurídica romana y la necesidad (y reales posibilidades científicas) de liberarse de ellos para emprender una investigación crítica de las fuentes jurídicas romanas, Giaro, T., "Über methodologische Werkmittel der Romanistik", en Zeitschrift der Savigny Stiftung für Rechtsgeschichte, romanistische Abteilung, t. cv, I988, I80 ss., I9I; Orestano, R., Introduzione allo studio del diritto romano, Bologna, Il Mulino, I 987,420 ss. Para la investigación histórico-jurídica y la influencia sobre ella de la ciencia pandectística véase Brutti, M., "Storiografia e critica del sistema pandettistico", en Quaderni fiorentini per la storia del pensiero giuridico moderno, t. VIII, I979, 3 I 7 ss. Fundamental sobre la metodología de la ciencia del derecho en perspectiva histórica y la construcción de un sistema jurídico Schröder, J., Recht als Wissenschaft. Geschichte der juristischen Methodenlebre in der Neuzeit (I50o-1933), 2. ${ }^{a}$ ed., München, C.H. Beck, 20 I 2. 
en dieciocho libros ${ }^{6}$, según se deduce del breve pero significativo relato contenido en el Enchiridion de Pomponio ${ }^{7}$. Entre las obras didácticas de época clásica destaca el -por así decirlo- sub-género de las Institutiones ${ }^{8}$ y, entre estas, las de Gayo (siglo II d.C.), que constituyen un caso único, tanto porque presentan una clara exposición del ius romanum sobre la base de la ars dialectica ${ }^{9}$ como porque han ejercido una enorme influencia en la construcción de los sistemas jurídicos de tradición europea-continental hasta la actualidad ${ }^{\circ}$. La opinión de MayerMaly, en el sentido de que Gayo habría sido the greatest systematising talent in Roman jurisprudence ${ }^{\mathrm{II}}$, tal vez encuentre su mayor justificación en esta última circunstancia, más que en el valor intrínseco del aporte de este Schuljurist a la

6 En este sentido, Krüger, P., Geschichte der Quellen und Litteratur des römischen Rechts, 2. ${ }^{a}$ ed., München/Leipzig, Duncker \& Humblot, I9 12, 64: "Das Hauptwerk des Scaevola, das Ius civile in achtzehn Büchern, war die erste systematische Zusammenfassung des Privatrechts". Cfr. también GuzMán Brito, El carácter dialéctico, cit., 428. Así, por ejemplo, las fuentes nos informan que el jurista tardorrepublicano habría distinguido entre varios genera tutelarum (Gai. I, I88) y genera possessionis (D. 4I,2,3,23 [Paul. 54 ad ed.]). Scarano Ussani, V., L'ars dei giuristi. Considerazioni sullo statuto epistemologico della giurisprudenza romana, Torino, Giappichelli, I 997, 56, habla a este respecto de una "metodologia ordinatoria", evitando el empleo de la expresión "sistema".

7 D. I,2,2,4I (Pomp. 1.s. enchir.): Post hos Quintus Mucius Publii filius pontifex maximus ius civile primus constituit generatim in libros decem et octo redigendo. Sobre el carácter científico de la obra de Q. Mucius Scaevola véase Schulz, Geschichte, cit., I I I ss.; Behrends, O., Die Wissenschaftslebre im Zivilrecht des Q. Mucius Scaevola pontifex, en Nachrichten der Akademie der Wissenschaften in Göttingen I. Philologisch-bistorische Klasse Nr. 7, Göttingen, Vandenhoeck \& Ruprecht, 1976, 3 ss.; Stein, P., "The Development of the Institutional System”, en íd./Lewis (eds.), Studies in Justinian's Institutes in memory of 7.A.C. Thomas, London, Sweet \& Maxwell, I983, I 5 I ss.; Schiavone, A., Giuristi e nobili nella Roma repubblicana. Il secolo della rivoluzione scientifica nel pensiero giuridico antico, Roma/Bari, Laterza, I992, 25 ss.

8 Las hay, además, de Gayo, de Florentino, de Paulo, de Calístrato, de Ulpiano y de Marciano. Véase, por todos, Schulz, Geschichte, cit., I 86 ss. También constituyen obras didácticas los libri tres iuris civilis de Masurio Sabino -ampliamente comentados en los siglos II y III por Aristón, Pomponio, Paulo y Ulpiano-, el ya mencionado Enchiridion de Pomponio y las res cottidianae de Gayo. Sobre el debate en torno a la efectiva autoría de Gayo de esta última obra véase en tiempos recientes - pronunciándose afirmativamente- Martini, R., "Gaio e le res cottidianae", Annali del Seminario Giuridico della Università di Palermo, t. Lv, 201 2, I 73 ss., I88: "come non ci siano differenze fra le Res cottidianae e le Institutiones gaiane tali da non conciliarsi con l'idea di un autore comune delle due opere". En términos similares se expresa Falcone, G., Obligatio est iuris vinculum, Torino, Giappichelli, 2003, 3 I ín., "Sistematiche gaiane e definizione di obligatio", en Capogrossi-Colognesi/Cursi (eds.), Obligatio-obbligazione. Un confronto interdisciplinare (Atti del Convegno di Roma 23-24 settembre 2010), Napoli, Jovene, 20 I I, I 7. La cuestión, por cierto, permanece abierta.

9 Guzmán Brito, El carácter dialéctico, cit., 427.

Io La literatura sobre este punto es inmensa y sería ocioso intentar presentar un elenco (necesariamente incompleto) en esta nota. Por ello, aquí me limito a hacer referencia a las breves pero informativas exposiciones de conjunto de WoŁodkiewicz, W., Les origines romaines de la systématique du droit civil contemporain, Wrocław/Warszawa/Kraków/Gdańsk, Zakład Narodowy Imienia Ossolińskich Wydawnictwo Polskiej Akad. Nauk, I978; y, en materia de obligaciones, en especial, De los Mozos Touya, J. J., "La clasificación de las fuentes de las obligaciones en las Instituciones de Gayo y de Justiniano y su valor sistemático en el moderno derecho civil", Seminarios Complutenses de Derecho Romano, t. vi, I994, I03 ss.

i I Mayer-Maly, T., “Divisio obligationum”, en The Irish Furist, t. II, I967, 38 I. 
iurisprudentia. En todo caso, el peso específico de las Instituciones de Gayo no debe ser menospreciado ni sobrevalorado ${ }^{12}$; esto cuenta en especial medida para la tradición clasificatoria de las obligaciones (divisiones obligationum) que arranca, precisamente, del manual gayano: las Gai Institutiones son la base de la construcción de una estructura del derecho de las obligaciones que, con independencia de diferencias temporales y locales, se ha mantenido vigente en la inmensa mayoría de las codificaciones civiles hasta la actualidad ${ }^{13}$.

Lo anterior, sin embargo, no vale en la misma medida para los juristas dedicados fundamentalmente a la enseñanza (los menos), como era el caso de Gayo $^{\mathrm{I}}$ : ellos debían explicar a sus discípulos los elementos centrales del ius civile de la forma más clara posible, y esto supone ordenar y clasificar, porque, como es bien sabido, quien no distingue, confunde. En este sentido, Kaser y Knütel han hablado con razón de la existencia de dos corrientes en el interior de la ciencia jurídica romana: una principal (Hauptströmung), orientada a la práctica y que se encontraría especialmente representada en las figuras de Juvencio Celso y Salvio Juliano (siglo II d.C.), y una secundaria (Nebenströmung), centrada en la formación jurídica elemental ${ }^{15}$.

I 2 Sobre la valoración de las Instituciones de Gayo ver Flume, W., "Die Bewertung der Institutionen des Gaius", Zeitschrift der Savigny Stiftung für Rechtsgeschichte, romanistische Abteilung, t. LXXIX, I962, I ss. Ve en el manual gayano la piedra angular del Corpus iuris civilis y, con ello, de nuestra concepción del derecho romano y su sistemática, STAGL, J. F., "Das didaktische System des Gaius", Zeitschrift der Savigny Stiftung für Rechtsgeschichte, romanistische Abteilung, t. cxxxI, 20I4, 3 I 3 ss. Crítico respecto de esta tesis Varvaro, M., "La dote, il ius singulare e il sistema didattico di Gaio", Seminarios Complutenses de Derecho Romano, t. xxix, 20 r6, 409 ss.

I 3 Véase, p. ej., von Lüвтоw, U., "Betrachtungen zum gajanischen Obligationenschema”, en Moschetti (ed.), Atti del Congresso Internazionale di Diritto Romano e di Storia del Diritto, Verona 27-28-29, IX, I948, III, Milano, Giuffrè, I95 I, 239 ss.; SARgenti, M., "La sistematica pregaiana delle obbligazioni e la nascita dell'idea di contratto", en Bona, Gallo, Goria, Lantella, íD., Scapini y Zannini (eds.), Prospettive sistematiche nel diritto romano, Torino, Giappichelli, i 976 , 455 ss.; Kaser, M., "Divisio obligationum”, en Stern/Lewis (ed.), Studies in Fustinian's Institutes in memory of J.A.c. Thomas, London, Sweet \& Maxwell, I983, 73 ss.; Paricio, J., "Las fuentes de las obligaciones en la tradición gayano-justinianea", en íD. (ed.), Derecho romano de obligaciones. Homenaje al profesor José Luis Murga Gener, Madrid, Centro de Estudios Ramón Areces, I 994, 49 ss.; De los Mozos Touya, La clasificación de las fuentes de las obligaciones, cit., IO3 ss.; Zimmermann, R., The Law of Obligations. Roman Foundations of the Civilian Tradition, Cape Town, Oxford University Press, I992; reimp. Oxford, I996, io ss.; Cannata, C. A., Materiali per un corso di fondamenti del diritto europeo II, Torino, Giappichelli, 2008, 9 ss.

I4 Lo cual no significa negar en principio el carácter clásico de las doctrinas expuestas por el jurista antoniniano y su relación con el ius controversum. Sobre el particular, véase en especial Kaser, M., "Gaius und die Klassiker", Zeitschrift der Savigny Stiftung für Rechtsgeschichte, romanistische Abteilung, t. LXx, I953, I 27 ss.; íD., "La classicità di Gaio", en Gaio nel suo tempo. Atti del simposio romanistico, Napoli, Jovene, I 966, 42 ss.; recientemente Brutti, M., "Gaio e il ius controversum", Annali del Seminario Giuridico della Università di Palermo, t. Lv, 201 2, 75 ss.

I 5 Kaser, M. y Knütel, R., Römisches Privatrecht, 20. a ed., München, C.H. Beck, 20 I4, 4. Sobre el modelo de enseñanza del derecho en la antigua Roma véase, p. ej., STolfi, E., "Die Juristenausbildung in der römischen Republik und im Prinzipat”, en Baldus, Finkenauer y Rüfner (eds.), Furistenausbildung in Europa zwischen Tradition und Reform, Tübingen, Mohr Siebeck, 2008, 9 ss. 
Obra cumbre de esta última corriente es, ciertamente, el manual gayano, las Gai Institutiones, estructuradas sobre la base de una tripartición de todo el derecho en aquel concerniente a las personas (personae), a las cosas (res) y a las acciones (actiones) ${ }^{\mathrm{I} 6}$. En el libro tercero, dedicado, al igual que el segundo, a las res, genus que se clasifica para efectos sistemático-didácticos en dos species, a saber, corporales e incorporales ${ }^{17}$, Gayo presenta su explicación de las obligaciones -en el contexto de las res incorporales ${ }^{18}$ - sobre la base de los hechos de los cuales estas emanan, es decir, sus causae, en el sentido específico de las actividades humanas concretas de las cuales nacen ${ }^{\mathrm{I} 9}$, lo que hoy en día denominamos como sus "fuentes". Aquí se encuentra la base de las clasificaciones de las causae obligationum de la así llamada tradición gayano-justinianea, compuesta, además de por las Instituciones de Gayo, por las res cottidianae ${ }^{20}$ y las Instituciones de Justiniano ${ }^{2 \mathrm{I}}$.

\section{Summa divisio obligationum y noción de contractus}

\section{A. La summa divisio de Gai. 3,88}

En el libro tercero de sus Institutiones, una vez concluido el tratamiento del derecho de sucesiones, Gayo comienza la explicación del derecho de obligaciones con una clasificación dialéctica del género obligatio en dos especies, lo que el maestro antoniniano denomina su summa divisio: Gai. 3,88: Nunc transeamus ${ }^{22}$ ad obligationes. Quarum summa divisio in duas species diducitur: omnis enim obligatio vel ex contractu nascitur vel ex delicto.

Pasemos ahora a las obligaciones, cuya suprema división establece dos especies: toda obligación nace de un contrato o de un delito.

I6 Gai. I,8: Omne autem ius, quo utimur, vel ad personas pertinet vel ad res vel ad actiones (...). Sobre esta clasificación dialéctica véase por todos Guzmán Brito, La tripartición del 'omne ius', cit., 2429 ss.

I 7 Gai. 2,I 2: Quaedam praeterea res corporales sunt, quaedam incorporales. Sobre las raíces filosóficas de esta clasificación de las cosas y su influencia en la jurisprudencia romana véase especialmente, en español, Guzmán Brito, A., Las cosas incorporales en la doctrina y en el derecho positivo, 2. 'ed., Santiago, Jurídica de Chile, 2006, in ss.

I 8 Gai. 2,I4: Incorporales sunt, quae tangi non possunt, qualia sunt ea, quae in iure consistunt, sicut hereditas, ususfructus, obligationes quoquo modo contractae.

I9 Cfr. Kaser, Divisio obligationum, cit., 73.

20 D. 44,7, I pr. (Gai. 2 res cott.). Sobre la atribución a Gayo de esta obra ver supra n. 8.

2 I I. 3,I 3,2. Una síntesis de esta tradición en De los Mozos Touya, La clasificación de las fuentes de las obligaciones, cit., IO3 ss.; PARICIO, Las fuentes de las obligaciones, cit., 49 ss.

22 Sobre el uso de la expresión nunc transeamus para designar el paso de una materia a otra en las Instituciones gayanas (cfr. Gai. I, I42; 2,246; 3, I 82) véase Nelson, H. L. W. y Manthe, U., Gai Institutiones III 88-I 8I. Die Kontraktsobligationen. Text und Kommentar, Berlin, Duncker \& Humblot, I999, 7 I. Para otras expresiones estereotípicas en el manual gayano véase Nelson, H. L. W., Überlieferung, Aufbau und Stil von Gai Institutiones, Leiden, Brill, I 98 I, 405 ss. 
El texto transcrito contiene la primera divisio obligationum propiamente dicha en la historia de la jurisprudencia romana ${ }^{2}$. En ella, Gayo se refiere a la clasificación más amplia posible, vale decir, aquella que incluye todas las obligaciones sin excepciones: su summa divisio. En efecto, para el maestro antoniniano no hay más especies de obligación fuera de los elementos de la divisio mencionados en este fragmento ${ }^{24}$; de lo contrario, esta no sería summa sino, en el mejor de los casos, maior. Las obligaciones admiten, pues, clasificación únicamente en dos grupos, según su causa: las nacidas de contrato y las nacidas de delito. Lo anterior se desprende con claridad del empleo de la expresión omnis obligatio, la que sin lugar a dudas debe ser interpretada en el sentido de "toda obligación".

Además, Gayo es consecuente al aplicar esta bipartición de las causae obligationum a las actiones in personam, toda vez que obligatio y actio son dos caras de la misma moneda: podemos ejercer una acción personal contra quien se encuentra obligado respecto de nosotros en virtud de un contrato o de un delito: Gai. 4,2: In personam actio est, qua agimus cum aliquo qui nobis vel ex contractu vel ex delicto obligatus est, id est cum intendimus dare facere praestare oportere.

Acción personal es aquella mediante la cual litigamos con alguien que está obligado respecto de nosotros en virtud de contrato o de delito; es decir, cuando pretendemos que debe dar, hacer o $\operatorname{prestar}^{25}$.

23 Véase, p. ej., Voci, P., La dottrina romana del contratto, Milano, Giuffrè, I946, 69; Cannata, C. A., "Sulla 'divisio obligationum' nel diritto romano repubblicano e classico", en Iura: Rivista internazionale di diritto romano e antico, t. xxi, I970, 52 ss.; Talamanca, M., "Obbligazioni (diritto romano)", Enciclopedia del Diritto, t. xxıx, Milano, Giuffrè, I979, 4I; Stein, The Development of the Institutional System, cit., I 5 I. En opinión de Cannata, Materiali II, cit., 73, Gayo habría creado su divisio obligationum "per amore della sistematica".

24 En este sentido ya Pernice, A., "Parerga III. Zur Vertragslehre der römischen Juristen”, Zeitschrift der Savigny Stiftung für Rechtsgeschichte, romanistische Abteilung, t. Ix, I888, I96 ss. Véase también SEGRÈ, G., "Sulla classificazione delle cause delle obligationes nelle Istituzioni di Gaio", en Rendiconti della Reale Accademia Nazionale dei Lincei v, serie vi, fasc. 3-4, 49 ss. = Scritti vari di diritto romano, Torino, Giappichelli, I952, 433 ss.; Lauria, M., "Contractus, delictum, obligatio (a proposito di recenti studi)", en Studia et Documenta Historiae et Iuris, t. IV, I938, I63 ss., I 72; Schulz, F., Classical Roman Law, Oxford, Oxford University Press, I95 I, 466 ss.; Grosso, G., Il sistema romano dei contratti, 3. ${ }^{\mathrm{a}}$ ed., Torino, Giappichelli, I963, 3 ss.; Wunner, S. E., Contractus. Sein Wortgebrauch und Willensgehalt im klassischen römischen Recht, Köln/Graz, Böhlau, I964, 42 ss. Para la bibliografía más reciente ver, p. ej., Paricio, Las fuentes de las obligaciones, cit., 49 ss.; ÍD., "Sull'idea di contratto in Gaio", en VACCA (ed.), Causa e contratto nella prospettiva storicocomparatistica, Torino, Giappichelli, I997, I 5 I ss., I 53 ; íD., Contrato. La formación de un concepto, Cizur Menor, Civitas, 2008, 28 ss.; Cannata, Materiali II, cit., 82 ss.

25 Cfr. D. 44,7,2 5, I (Ulp. l.s. reg.): Actionum autem quaedam ex contractu, quaedam ex facto, quaedam in factum sunt. Ex contractu actio est, quotiens quis sui lucri causa cum aliquo contrabit, veluti emendo vendendo locando conducendo et ceteris similibus. Ex facto actio est, quotiens ex eo teneri quis incipit, quod ipse admisit, veluti furtum vel iniuriam commisit vel damnum dedit. In factum actio dicitur, qualis est exempli gratia actio, quae datur patrono adversus libertum, a quo contra edictum praetoris in ius vocatus est. El pseudo-ulpianeo liber singularis Regularum (también conocido como Tituli ex corpore Ulpiani) depende en gran medida de las Instituciones de Gayo, o bien de una tradición escolar común a Gayo. Para las distintas hipótesis sobre la relación entre ambas obras ver Nelson, Überlieferung, Aufbau und Stil, cit., 86 ss., 338 ss. Mercogliano, F., 'Tituli ex corpore Ul- 
El fragmento transcrito expresa esencialmente la misma idea que Gai. 3,88, solo que desde la perspectiva de la actio y no de la obligatio; un diverso punto de vista que, en todo caso, no debió presentar mayores dificultades para los clásicos, quienes no conocieron la moderna distinción entre derecho material y derecho formal ${ }^{26}$. Es por ello que sin temor a equivocarnos podemos asumir que cuando los juristas romanos hablaban de obligatio también querían decir actio (in personam, se entiende), y al referirse a la actio estaban diciendo al mismo tiempo obligatio. En efecto, Salvio Juliano nos enseña en sus libri digestorum que respecto de las así llamadas obligaciones naturales, que no engendran acción sino solamente excepción, solo impropiamente (per abusionem) se dice que los deudores naturales “deben", y que a quienes se entrega una cantidad de dinero recibieron lo que verdaderamente se les "debía” 27 . Para expresarlo en otros términos, según Juliano, los deudores naturales no son verdaderos debitores, y los acreedores naturales no son creditores $^{28}$ propiamente dichos. De lo anterior se colige que el término

piani'. Storia di un testo, Napoli, Jovene, I997, I3 ss.; Avenarius, M., Der pseudo-ulpianische liber singularis regularum. Entstehung, Eigenart und Überlieferung einer hochklassischen Furistenschrift, Göttingen, Wallstein, 2005, 36 ss.; en el marco de una completa revisión e integración de Fontes Iuris Romani Anteiustiniani (FIRA), proyecto dirigido por la sección de Historia del Derecho de la Universidad de Palermo, Mattioli, F., "Un tentativo di messa a punto riguardo alla più recente dottrina sui Tituli ex corpore Ulpiani. Ipotesi e prospettive di ricerca", en Purpura (ed.), Revisione ed integrazione dei Fontes Iuris Romani Anteiustiniani (FIRA). Studi preparatori II. Auctores - Negotia, Torino, Giappichelli, 20I2, 85 ss. La fuente citada contiene una clasificación de las actiones in personam (las actiones in rem, de las que se hace mención en el principium del fragmento, se encuentran excluidas de esta clasificación). Aquí se distingue en primer lugar entre las acciones civiles que emanan de contrato o de delito, empleándose para estas últimas la denominación actio ex facto. Ambas clases de acciones, en cuanto civiles, se contraponen a las actiones in factum. Pues bien, todos los facta mencionados en el texto de los cuales puede surgir una acción ex facto consisten en hechos ilícitos típicos, a saber, el hurto (furtum), el daño a las personas (iniuria) y el daño en las cosas (damnum). Lo anterior implica que el fundamento de las actiones ex facto consiste en un acto ilícito generador de obligaciones, lo que permite traducir el término actio ex facto como actio ex delicto, que solo se contrapone -en el ámbito de las acciones civiles- a la actio ex contractu, que sería la que procede de un acto lícito generador de obligaciones. Lo dicho se corresponde perfectamente con la clasificación de las acciones personales presente en Gai. 4,2.

26 Enfático en este sentido, Lombardi, L., Saggio sul diritto giurisprudenziale, Milano, Giuffrè, 1967, I: "Con diritto privato va intesa, per Roma, la dinamica unità formata dal diritto materiale e dal diritto processuale (sarebbe forse meglio dire, romanamente, 'azionale'), che non si prestano ad essere capiti e studiati indipendentemente l'uno dall'altro". Sobre el problema de la interdependencia entre "derecho procesal" y "derecho material" en la antigua Roma véase también NörR, D., "Zur Interdependenz von Prozeßrecht und materiellem Recht am Beispiel der lex Aquilia", en Chiusi, Kaiser y Spengler (eds.), Historiae iuris antiqui III, Goldbach, Keip, 2003, I727 ss. En detalle sobre el desarrollo histórico de esta moderna distinción sistemática Kollmann, A., Begriffs- und Problemgeschichte des Verbältnisses von formellem und materiellem Recht, Berlin, Duncker \& Humblot, 1996, 27 ss.

27 D. 46,I, I6,4 (Iul. 53 dig.): Naturales obligationes non eo solo aestimantur, si actio aliqua eorum nomine competit, verum etiam cum soluta pecunia repeti non potest: nam licet minus proprie debere dicantur naturales debitores, per abusionem intellegi possunt debitores et, qui ab bis pecuniam recipiunt, debitum sibi recepisse.

28 Para la noción de creditor como "acreedor" sin más, con independencia de la fuente de su acreencia, véase Gai. 3, I 24; D. 50,16,10 (Ulp. 6 ad ed.) y D. 50, I6, I I (Gai. I ad ed. prov.). 
obligatio es empleado en modo impropio (abusivo, como dice el jurista) respecto de los vínculos no amparados por una actio in personam o, lo que es lo mismo, que toda obligación en sentido propio supone una acción.

Por consiguiente, de los fragmentos de las Gai Institutiones anteriormente citados se desprende la exclusión de todo posible tertium quid entre contractus y delictum: no hay obligación ni, por tanto, acción personal (dos perspectivas distintas de la misma realidad), que no proceda de un contrato o de un delito ${ }^{29}$. Por lo demás, Gayo confirma este significado del sintagma summa divisio en otros pasajes de su obra, a saber, en Gai. I,9 en materia de derecho de las personas (summa divisio personarum) ${ }^{30}$ y en Gai. 2,2 con respecto al derecho de las cosas (summa divisio rerum $)^{3 \mathrm{I}}$. El innegable carácter omnicomprensivo de la división de las personas entre libres y esclavos, por una parte, y de la división de las cosas entre aquellas de derecho divino y aquellas de derecho humano, por la otra, constituye un argumento suficientemente sólido a favor de la tesis de que Gayo quiso presentar una divisio igualmente completa en Gai. $3,88^{\left[3^{2}\right]}$. Además, si tenemos presente que para Gayo todo el derecho se divide en personae, res y actiones, y que tanto las personas como las cosas han sido objeto de summae divisiones que, respectivamente, cubren todos los supuestos, ya que no hay personas que no sean libres o esclavos, así como tampoco hay cosas que no se circunscriban al derecho divino o humano, lo mismo cabe esperar del tercer elemento de la tripartición, a saber, las acciones, respecto de las cuales -al menos en lo concerniente a las personales y, por ende, a las obligaciones- Gayo se preocupa de explicitar -en plena concordancia con Gai. 3,88- que solo pueden emanar de un contrato o de un delito (Gai. 4,2).

En consecuencia, en Gai. 3,88 y 4,2 el maestro antoniniano presenta una (para el dogmático moderno) noción amplísima de contrato, construida exclusivamente sobre la base de su contraposición al delito, en el sentido de que toda causa de obligación que no sea constitutiva de un hecho ilícito (delictum) será susceptible de ser calificada sin más como contractus. Dicho en otros términos: la idea de contrato contenida en Gai. 3,88 -y confirmada en Gai. 4,2- corresponde

29 Cfr. Gai. 4, I I 2-I I 3, donde vuelve a apreciarse la divisio entre acciones ex maleficio (4, I I 2) y ex contractu (4, I I3), con apariencia de omnicomprensión.

30 Gai. I,9: Et quidem summa divisio personarum haec est, quod omnes bomines aut liberi sunt aut servi. Digna de destacar es la expresión quidem (ciertamente, sin duda), con la cual Gayo busca afirmar la validez de su divisio. Cfr. Vincenti, U., Categorie del diritto romano, Napoli, Jovene, 2007, I 9 ss.; PARICIO, Contrato, cit., p. 29.

3 I Gai. 2,2: Summa itaque rerum divisio in duos articulos diducitur: nam aliae sunt divini iuris, aliae bumani. Esta forma de expresarse puede compararse con la utilizada por Ulpiano en D. 50, I6, I 95, I (Ulp. 46 ad ed.): 'Familiae' appellatio (...) et in res et in personas deducitur. Cfr. Nelson/Manthe, Gai Institutiones, cit., 7 I; Vincent, Categorie, cit., 48 ss.

32 Cfr. Schulz, Classical Roman Law, cit., 466; PARicio, Las fuentes de las obligaciones, cit., 49; íD., Contrato, cit., 30 . 
a todo hecho lícito que engendra obligaciones ${ }^{33}$. Y decimos que esta noción de contrato es amplísima para el dogmático moderno debido a que Gayo, según veremos a continuación, califica como contractus a ciertas figuras negociales con total prescindencia de si existe o no un acuerdo de voluntades (conventio)34; se trata, por ende, de supuestos que, vistos con el prisma del jurista contemporáneo, heredero de la tradición del ius commune ${ }^{35}$, mal podrían ser calificados como parte de la categoría de fuentes de las obligaciones denominada contrato, ya que para nosotros este se encuentra constituido esencialmente por una convención ${ }^{36}$. No ocurre lo mismo, en cambio, cuando se analizan las fuentes jurídicas romanas

33 Estamos de acuerdo en esto con Schulz, Classical Roman Law, cit., 466: "Obviously this is a classification of all possible obligations; consequently contractus must need embrance any legal act from which obligations resulted, delicts alone being excluded". En el mismo sentido, más recientemente, Paricio, Contrato, cit., 34: "Así pues, aunque Gayo no incluya una definición de contrato, parece claro que tiende a configurarlo como una categoría donde se engloban todos los actos lícitos reconocidos por el ius civile, convencionales o no convencionales, destinados a crear un vínculo obligatorio, al margen del cual, y como contrapuesto a él, queda el ámbito de los delitos". Cfr. también, sobre la noción gayana de contrato, no fundada en el consensus, íd., Sull'idea di contratto in Gaio, cit., I 5 I ss.; SARgentr, M., "Svolgimento dell'idea di contratto nel pensiero giuridico romano", Iura: Rivista internazionale di diritto romano e antico, t. XxxIx, I988, 24 ss., 56; MARTINI, R., "Il mito del consenso nella dottrina del contratto", Iura: Rivista internazionale di diritto romano e antico, t. XLII, I99I, 97 ss.

34 La doctrina según la cual en la base de todo contrato habría una convención encuentra su expresión más fiel en D. 2,I4,I,3 (Ulp. 4 ad ed.), fragmento en el cual Ulpiano se remite a una -a su juicio- "elegante" afirmación de Sexto Pedio: Conventionis verbum generale est ad omnia pertinens, de quibus negotii contrahendi transigendique causa consentiunt qui inter se agunt: nam sicuti convenire dicuntur qui ex diversis locis in unum locum colliguntur et veniunt, ita et qui ex diversis animi motibus in unum consentiunt, id est in unam sententiam decurrunt. adeo autem conventionis nomen generale est, ut eleganter dicat Pedius nullum esse contractum, nullam obligationem, quae non babeat in se conventionem, sive re sive verbis fiat: nam et stipulatio, quae verbis fit, nisi habeat consensum, nulla est. Esta noción no logró jamás consolidarse como única en la jurisprudencia clásica, además de que -dicho sea de paso- en caso alguno identifica los conceptos contrato y convención, sino que se limita a plantear que en todo contractus habría una conventio, que no es lo mismo, ya que hay también convenciones no contractuales, en la medida que no están amparadas por una actio, como es el caso de los pacta nuda. Una síntesis sobre esta fuente y su relevancia en la historia del concepto romano de contrato en Garofalo, L., "Contratto, obbligazione e convenzione in Sesto Pedio", en Burdese (ed.), Le dottrine del contratto nella giurisprudenza romana, Padova, Cedam, 2006, 337 ss.; Paricio, Contrato, cit., 77 ss.

35 Para la construcción de un sistema contractual en el ius commune ver especialmente Volante, R., Il sistema contrattuale del diritto comune classico. Struttura dei patti e individuazione del tipo. Glossatori e ultramontani, Milano, Giuffrè, $200 \mathrm{I}$.

36 Así lo dispone expresamente, por lo demás, el artículo I 438 cc. chileno (= art. I 495 cc. col.): "Contrato o convención es un acto por el cual una parte se obliga para con otra a dar, hacer o no hacer alguna cosa. Cada parte puede ser una o muchas personas". Para el desarrollo de la moderna noción de contrato fundada en el consensus ver, especialmente, Nanz, K.-P., Die Entstehung des allgemeinen Vertragsbegriffs im 16. bis I8. Jahrbundert, München, Schweitzer, I985, 5 ss.; Kegel, G., Vertrag und Delikt, München, Heymanns, 2002, 3 ss.; para sus fundamentos filosóficos, Gordery, J., The Philosophical Origins of Modern Contract Doctrine, Oxford, Oxford University Press, I991, Io ss. 
libres (en la medida de lo posible) de prejuicios pandectistas ${ }^{37}$. Una premisa metodológica básica de la investigación iusromanística es que no hay que buscar en las fuentes romanas el sistema jurídico que nosotros a priori quisiéramos tener: el sistema de la pandectística no es el mismo de las Pandectas ${ }^{3}$.

\section{B. La noción "gayana" de contractus en otros pasajes de las Institutiones}

La idea de contrato precedentemente expuesta, esto es, la identificación del contractus sin más con todo hecho lícito que genera obligaciones (un "no-delito"), sin que sea necesario que medie un acuerdo de voluntades, encuentra aplicación en otros pasajes de las Instituciones de Gayo, los que a su vez se ven refrendados en fragmentos de la jurisprudencia tardo-clásica, en concreto, de Paulo y Ulpiano (siglo III d.C.), que tratan, respectivamente, sobre las mismas figuras.

Así ocurre, en primer lugar, con la tutela (tutela). En Gai 4,I 82 se incluye una lista incompleta de acciones infamantes ${ }^{39}$; en ella, el jurista menciona las actiones emanadas de hurto (furti), rapiña (vi bonorum raptorum) e injuria o daño en las personas (iniuriarum), por una parte, y las actiones pro socio, fiduciae, tutelae, mandati y depositi, por la otra. Luego, y aquí está lo relevante, Gayo agrega que no es lo mismo ser deudor -vale decir, estar obligado (en el sentido propio del término)- por contrato que por delito: utrum ex delicto aliquis an ex contractu debitor sit. Las primeras tres acciones son tratadas como delictuales, a fin de explicar un rasgo procesal común relacionado con la transacción. En este contexto, las demás acciones mencionadas no pueden sino formar parte del otro elemento de la dicotomía, vale decir, los casos en los cuales una persona es deudora (se obliga) en virtud de un contrato; de lo contrario, la distinción expuesta por Gayo en el fragmento no tendría sentido. A este segundo grupo de acciones pertenece, pre-

37 Sobre el peligro de llevar a cabo construcciones dogmático-sistemáticas anacrónicas en la interpretación de las fuentes jurídicas romanas ver en especial -además de la bibliografía citada en n. 5- Hoetink, H. R., "Über anachronistische Begriffsbildung in der Rechtsgeschichte", Zeitschrift der Savigny Stiftung für Rechtsgeschichte, romanistische Abteilung, t. LxxII, I955, 39 ss.; Nörr, K. W., "Das römische Recht zwischen Technik und Substanz: Bemerkungen zu seiner Rolle am Ende des 20. Jahrhunderts", Zeitschrift für Europäisches Privatrecht, t. II, I 994, 67 ss.; Avenarius, M., "Tradition, Vorverständnis und Wirkungsgeschichte der Quellen. Vom Einfluß der geisteswissenschaftlichen Hermeneutik auf das romanistische Verstehen”, en íD. (ed.), Hermeneutik der Quellentexte des Römischen Rechts, Baden-Baden, Nomos, 2008, 9 ss.

$3^{8}$ En este sentido Baldus, C., "Zum Begriff des debitum bei Cervidius Scaevola. Schuldrecht, Erbrecht und Prozessrecht zwischen Hochklassik und Spätklassik", en Harke (ed.), Facetten des römischen Erbrechts, Berlin/Heidelberg, Springer, 20 I 2, 34.

39 Gai. 4, 8 82: Quibusdam iudiciis damnati ignominiosi fiunt, uelut furti, ui bonorum raptorum, iniuriarum, item pro socio, fiduciae, tutelae, mandati, depositi. sed furti aut ui bonorum raptorum aut iniuriarum non solum damnati notantur ignominia, sed etiam pacti, ut in edicto praetoris scriptum est; et recte. plurimum enim interest, utrum ex delicto aliquis an ex contractu debitor sit. nec tamen ulla parte edicti id ipsum nominatim exprimitur, ut aliquis ignominiosus sit, sed qui probibetur et pro alio postulare et cognitorem dare procuratoremue habere, item procuratorio aut cognitorio nomine iudicio interuenire, ignominiosus esse dicitur. 
cisamente, la actio tutelae, de modo tal que la relación obligatoria a que da lugar la tutela entre pupilo y tutor -y que se encuentra protegida por una acción in ius concepta ex fide bon $a^{4 \circ}$, a la que hace alusión el texto- necesariamente debe ser incluida entre las obligationes ex contractu, puesto que el jurista no nos ofrece, ni aquí ni en Gai. 4,2, una tercera posibilidad: la obligación -o acción personal- que no es delictual solo puede ser contractual.

Como hemos adelantado, el carácter contractual de la tutela no solo se refleja en las Instituciones de Gayo, sino también en fragmentos jurisprudenciales de Ulpiano ${ }^{4}$ y Paulo42.

Otro tanto puede decirse respecto de la dote $(d o s)$, para la cual no se requiere estructuralmente un acuerdo de voluntades. En efecto, la dotis dictio, modo especialísimo de constitución de la dote en la antigua Roma, distinto de la directa transferencia de dominio sobre los bienes dotales (datio dotis) y de la stipulatio (promissio dotis), consiste en una promesa unilateral solemne generadora de obligaciones, que tiene lugar - a diferencia de la estipulación- uno loquente, nulla praecedente interrogatione. Ello no impide a Gayo, empero, utilizar respecto de esta figura el verbo contrabere ${ }^{43}$, lo que nos induce a asumir que aquí el jurista veía un supuesto contractual, en la medida que, evidentemente, no se había configurado un hecho ilícito. El carácter contractual de la dote puede apreciarse también, fuera de las Instituciones gayanas, en un fragmento de Ulpiano, en el cual el jurista severiano probablemente reproduce una opinión de Masurio Sabino (siglo I d.C.): aquí se incluye la dote derechamente entre los contratos (et quidem in contractibus...), específicamente aquellos en que la responsabilidad del deudor se extiende tanto al dolo como a la culpa (et dolus et culpa praestatur), por aplicación de la regula de la utilitas contrabentium (ubi utriusque utilitas vertitur) ${ }^{44}$.

40 De acuerdo al catálogo de acciones de buena fe contenido en Gai. 4,62.

4I D. I3,5, I,6 (Ulp. 27 ad ed.): Debitum autem ex quacumque causa potest constitui, id est ex quocumque contractu sive certi sive incerti, et si ex causa emptionis quis pretium debeat vel ex causa dotis vel ex causa tutelae vel ex quocumque alio contractu; D. 50,17,23 (Ulp. 29 ad Sab.): Contractus quidam dolum malum dumtaxat recipiunt, quidam et dolum et culpam. dolum tantum: depositum et precarium. dolum et culpam mandatum, commodatum, venditum, pignori acceptum, locatum, item dotis datio, tutelae, negotia gesta (...).

42 D. 44,7,49 (Paul. I 8 ad Plaut.): Ex contractibus venientes actiones in heredes dantur, licet delictum quoque versetur, veluti cum tutor in tutela gerenda dolo fecerit aut is apud quem depositum est (...).

43 Gai. 3,95a: Sunt et aliae obligationes quae nulla praecedente interrogatione contrabi possunt (...) si debitor mulieris iussu eius, dum (...) doti dicat quod debet (...).

44 D. I3,6,5,2 (Ulp. 28 ad ed.): Nunc videndum est, quid veniat in commodati actione, utrum dolus an et culpa an vero et omne periculum. et quidem in contractibus interdum dolum solum, interdum et culpam praestamus (...) sed ubi utriusque utilitas vertitur, ut in empto, ut in locato, ut in dote, ut in pignore, ut in societate, et dolus et culpa praestatur. Cfr. nuevamente D. I 3,5, I,6 (Ulp. 27 ad ed.) (texto citado supra, n. 4I), además de D. 50, I 7,23 (Ulp. 29 ad Sab.). Una síntesis sobre la utilitas contrabentium en el pensamiento jurídico romano y su importancia para la tradición romanística posterior en materia de responsabilidad contractual en SANTUCCI, G., "Utilitas contrahentium. Note minime su una regula che 'cacciata dalla porta rientrò dalla finestra", en Fioni (ed.), Modelli teorici e metodologici nella storia del diritto privato 3, Napoli, Jovene, 2008, 277 ss. Aquí se encuentra el 
Por su parte, en lo que concierne a la gestión de negocios ajenos o agencia oficiosa (negotiorum gestio), esta se caracteriza tanto por la intención de -como su nombre lo indica- gestionar uno o más negocios de un tercero, como por la utilidad que presta a este último. Desde esta perspectiva, por tanto, la negotiorum gestio se acerca muchísimo no solo en sus efectos, sino también en los aspectos esenciales de su estructura jurídica, al mandato (mandatum) ${ }^{45}$. La diferencia entre ambos supuestos radica, evidentemente, en que la negotiorum gestio no se funda en un acuerdo de voluntades, mientras que el mandatum constituye un caso de obligatio consensu contracta ${ }^{6}$, pero fuera de este aspecto no se aprecian diferencias determinantes 47 . La falta de acuerdo de voluntades en la gestión de negocios solo se aprecia como esencial a los ojos del dogmático moderno, que parte de la idea apriorística de que todo contrato es una convención. Es más, entre los primeros casos de aplicación de la negotiorum gestio se encontraba la protección del patrimonio por parte de un procurator omnium bonorum en ausencia del demandado ${ }^{4}$, lo que esencialmente debió corresponder a la imagen de una obligación consensual49.

Ahora bien, debemos reconocer que las Instituciones de Gayo no ofrecen argumentos explícitos a favor de la naturaleza contractual de la gestión de negocios ajenos. La actio negotiorum gestorum apenas aparece mencionada en esta obra, y cuando recibe alguna atención, ello es de manera inusualmente asistemática; en efecto, se menciona esta acción con respecto a la distinción entre las actiones, quae ad legis actionem exprimuntur (comúnmente denominadas fictae legis actiones) y aquellas que sua vi ac potestate constant $5^{\circ}$, o bien entre las fórmulas de buena fe (bonae fidei iudicia) ${ }^{5}{ }^{\mathrm{I}}$. Sin embargo, el carácter contractual de la gestión de negocios ajenos no puede ser descartado de antemano simplemente por la ausencia

origen remoto de la graduación de la culpa consagrada en el artículo I 547 cc. chileno (= art. r604 cc. col.). En detalle sobre el desarrollo histórico de la graduación de la culpa en la tradición romanística, Hof fmann, H.-J., Die Abstufung der Fabrlässigkeit in der Rechtsgeschichte. Unter besonderer Berücksichtigung der culpa levissima, Berlin, Walter de Gruyter, I968.

45 En este sentido Harke, J. D., Geschäftsführung und Bereicherung, Berlin, Duncker \& Humblot, 2007,9 s., quien se refiere a la negotiorum gestio como una "vertragsähnliche Kombination von Fremdgeschäftsfïhrungswillen und Nützlichkeit", en la cual se habrían concentrado los juristas alto y tardo-clásicos (siglos II y III d.C., según la periodización de la jurisprudencia romana habitual en la romanística alemana). Consecuentemente íD., Römisches Recbt. Von der klassischen Zeit bis zu den modernen Kodifikationen, 2. ${ }^{a}$ ed., München, C.H. Beck, 20I6, I 77, ve en la negotiorum gestio, el mandatum y la societas una unidad orientada a hacer efectivas las relaciones jurídicas gratuitas ("die unentgeltlichen Rechtsbeziehungen zu bewältigen").

46 Gai. $3, \mathrm{I} 35$.

47 HaRke, Geschäftsfübrung und Bereicherung, cit., 9.

48 Véase D. 3,5, I (Ulp. ro ad ed.).

49 Harke, Geschäftsfübrung und Bereicherung, cit., 9. Cfr. SeILER, H. H., Der Tatbestand der negotiorum gestio im römischen Recht, Köln/Graz, Böhlau, I 968, ı०9 s.

50 Gai. 4,33 . Se trata de acciones con formula ficticia.

5 I Gai. 4,62 . 
de conventio: en un orden sistemático como el de las Instituciones de Gayo, que no conoce causas de obligación distintas del contrato y el delito, la negotiorum gestio, en cuanto acto lícito generador de obligaciones, solo puede ser calificada como contractus, puesto que sin lugar a dudas no es constitutiva de un delictum ${ }^{2}$. La gestión de negocios ajenos es, en realidad, plenamente compatible con la idea de contrato que se desprende de Gai. 3,88, así como la acción respectiva es contractual en los términos de Gai. 4,2. Lo que hemos dicho respecto de la tutela y la dote debe valer igualmente para la gestión de negocios.

A lo dicho cabe agregar que el carácter contractual de la negotiorum gestio es confirmado tanto por Ulpiano 53 como por Paulo54.

52 Paricio, Contrato, cit., 33.

53 Se trata de dos textos. El primero, D. I I,7, I (Ulp. io ad ed.), reza como sigue: Qui propter funus aliquid impendit, cum defuncto contrahere creditur, non cum berede. Si bien este fragmento no está situado en el título quinto del libro tercero del Digesto (de negotiis gestis), sino en el título de religiosis et sumptibus funerum et ut funus ducere liceat, no cabe duda de que su contexto originario era la explicación de la gestión de negocios ajenos; lo anterior, debido a que fue extraído por los compiladores del décimo libro del comentario de Ulpiano al edicto del pretor urbano, que versaba, precisamente, sobre la gestión de negocios, mas no sobre la acción funeraria, de la que trataba el vigésimo quinto libro de dicho comentario. Esto, en todo caso, no debe sorprender, si se tiene en cuenta que el título edictal de negotiis gestis (título viII $\$ 35$ según la reconstrucción de Lenel) contenía un apartado sobre negotia quae cuiusque cum is moritur fuerint. Cfr. Lenel, O., Palingenesia iuris civilis II, Leipzig, Bernhard Tauschnitz, I 889, c. 459 (nr. 358); íD., Das Edictum perpetuum. Ein Versuch zu seiner Wiederherstellung, $3 .{ }^{a}$ ed., Leipzig, Bernhard Tauschnitz, 1927 , io i ss.; Cenderelli, A., La negotiorum gestio. Corso esegetico di diritto romano i. Struttura, origini, azioni, Torino, Giappichelli, I997, 75 ss. Como puede apreciarse, el jurista severiano emplea la expresión contrahere para hacer alusión a la obligación nacida de negotiorum gestio. El segundo texto es D. 50,17,23 (Ulp. 29 ad Sab.): Contractus quidam dolum malum dumtaxat recipiunt, quidam et dolum et culpam. dolum tantum: depositum et precarium. dolum et culpam mandatum, commodatum, venditum, pignori acceptum, locatum, item dotis datio, tutelae, negotia gesta (...). Aquí, la calificación de la gestión de negocios como contrato -se emplea el sustantivo contractus- es explícita; lo mismo cabe para la tutela y la dote.

54 D. 3,5,I 5 (Paul. 7 ad Plaut.): Sed et cum aliquis negotia mea gerat, non multa negotia sunt, sed unus contractus, nisi si ab initio ad unum negotium accessit, ut finito eo discederet: hoc enim casu si nova voluntate aliquid quoque adgredi coeperit, alius contractus est. Se trata de un fragmento extraído de los libri ad Plautium de Julio Paulo, una obra altamente valorada por los compiladores justinianeos, como demuestran los 177 fragmentos incluidos en el Digesto. El libro séptimo ad Plautium no tenía por objeto propio la negotiorum gestio, sino la tutela (cfr. Lenel, O., Palingenesia Iuris Civilis I, Leipzig, Bernhard Tauschnitz, I 889, c. I 58 [nr. I I 35]). A partir del título de la obra no puede descartarse que el propio Plaucio haya calificado la negotiorum gestio como contractus, opinión que luego habría sido secundada por Paulo. Después de todo, este último afirma el carácter contractual de la tutela, precisamente, en otro texto extraído de sus libri ad Plautium, precedentemente citado (D. 44,7,49 [Paul. i 8 ad Plaut.]; ver n. 42). Es más, la ausencia en la fuente de remisiones explícitas al pensamiento de su antecesor, que en cambio sí se encuentran en otros fragmentos del comentario ad Plautium, tales como Plautius ait o apud Plautium placuit, permiten sostener con un alto grado de verosimilitud que, en este caso, Paulo está manifestando su propia opinión y no (solamente) la de Plaucio. En este sentido cfr. Cenderelli, La negotiorum gestio, cit., 7 I ss.; FinazzI, G., Ricerche in tema di negotiorum gestio II.I. Requisiti delle actiones negotiorum gestorum, Napoli, Jovene, 2003, 7 I ss. La habitual exactitud terminológica con que se conduce Paulo conspira contra la hipótesis de un uso descuidado del concepto contractus en el texto transcrito, con mayor razón si se tiene en cuenta que no recurre a él una, sino dos veces en pocas líneas. 
Finalmente, podemos agregar el caso del pago de lo no debido (solutio indebiti). El pago de lo no debido, es decir, la ejecución motivada por error de una obligación inexistente, ya sea absoluta o relativamente, es presentada por Gayo en sus Institutiones como causa de una "obligación real", vale decir, constituida mediante la transferencia de dominio de una cosa (datio rei en sentido estricto) ${ }^{55}$ : Is quoque, qui non debitum accepit ab eo, qui per errorem solvit, re obligatur ${ }^{6}$. El motivo de ello radica en su clara semejanza estructural con la mutui datio, la dación de cosas fungibles en mutuo ${ }^{57}$ : la solutio indebiti consiste en una transferencia de dominio (datio rei: en Gai. 3,9 I se dice expresamente si paret eum dare oportere) y la pretensión del solvens en cuanto a la restitución de lo indebidamente pagado se hace valer mediante el ejercicio de la condictio (nam proinde ei condici potest), como si el accipiens hubiese adquirido en mutuo (ac si mutuum accepisset). Ahora bien, el empleo de la palabra quoque (igualmente, asimismo) pareciera significar que la solutio indebiti constituye una obligatio re contracta al igual que la mutui datio (Gai. 3,90). Después de todo, de acuerdo al esquema gayano, no siendo la solutio indebiti un supuesto contrario a derecho (delictum), no le queda otra alternativa que ser calificada como contractus $^{8}$. Sin embargo, Gayo expresa una reserva, señalando que pareciera que en este caso no se estaría realmente en presencia de una obligación de carácter contractual (non videtur ex contractu consistere), y la razón estriba en que quien transfiere en dominio de una cosa con la intención de cumplir una obligación, más quiere extinguir una relación obligatoria que contraerla (en el sentido de hacerla nacer): quia is, qui solvendi animo dat, magis distrabere vult negotium quam contrabere. De una supuesta falta de acuerdo de voluntades como razón para que Gayo excluyera a la solutio indebiti de los supuestos de obligatio ex contractu, no hay testimonio en las fuentes; los reparos de Gayo no están en hacer notar la falta de una conventio, sino en la "falta de intención vinculativa" del

55 Numerosas fuentes atestiguan que el significado técnico-jurídico de dare rem en derecho romano consistía en la transferencia de dominio de una cosa, no en su mera entrega. Así, p. ej., Gai. 2,204; 4,4; D. I 7,I,47, I (Pomp. 3 ex Plaut.); D. $22, \mathrm{I}, 4$ pr. (Pap. 27 quaest.); D. 32,29, 3 (Lab. 2 post. a Iav. epit.); D. 45,I,75, IO (Ulp. 22 ad ed.); D. 50, I 7,I67 pr. (Paul. 49 ad ed.). En detalle sobre el significado de re obligari como constitución de una relación obligatoria mediante la transferencia del dominio, Wegmann Stockebrand, A., Obligatio re contracta. Ein Beitrag zur sogenannten Kategorie der Realverträge im römischen Recht, Tübingen, Mohr Siebeck, 20 I 7, I I 5 ss.

${ }_{5} 6$ Gai. 3,9I: Is quoque, qui non debitum accepit ab eo, qui per errorem solvit, re obligatur; nam proinde ei condici potest SI PARET EVM DARE OPORTERE, ac si mutuum accepisset. Unde quidam putant pupillum aut mulierem, cui sine tutoris auctoritate non debitum per errorem datum est, non teneri condictione, non magis quam mutui datione. Sed haec species obligationis non videtur ex contractu consistere, quia is, qui solvendi animo dat, magis distrabere vult negotium quam contrabere.

57 Gai. 3,90: Re contrabitur obligatio uelut mutui datione (...). Para los rasgos fundamentales de la solutio indebiti y su relación con la mutui datio ver, además de Gai. 3,9 I, por ejemplo, D. I 2,6, I, I (Ulp. 26 ad ed.); D. г 2,6,26,3 (Ulp. 26 ad ed.); D. г 2,6,65,9 (Paul. I 7 ad Plaut.); FV 266 (Ulp. 26 ad ed.).

$5^{8}$ En este sentido también Laborenz, M., Solutio als causa. Die Frage des Abstraktionsprinzips im römischen Recht, Köln/Weimar/Wien, Böhlau, 20 I4, 234. 
solvens, que es una cosa distinta ${ }^{59}$. En síntesis: el maestro antoniniano pone en entredicho la naturaleza contractual de la solutio indebiti específicamente porque el solvens no busca crear una obligación nueva, sino precisamente lo contrario, extinguir una que cree existente; pero, como para Gayo el contrato es una de las dos maneras en que se puede hacer nacer una obligación (Gai. 3,88: omnis enim obligatio vel ex contractu nascitur vel ex delicto), un supuesto de distrabere mal podría formar parte de la categoría del contrahere. Es por este motivo, y no por otro, que para Gayo la solutio indebiti no consiste en un contractus $^{60}$.

\section{La noción "gayana" de contractus en otras fuentes de la jurisprudencia clásica}

Como hemos adelantado, a nuestro entender la bipartición contractus-delictum contenida en Gai. 3,88 no es una rareza de Gayo en el marco de la jurisprudencia romana, ni tampoco una mera simplificación de las cosas con fines puramente didácticos. Tal opinión, demasiado extendida en la romanística ${ }^{6 \mathrm{I}}$, parte de la premisa -que se encuentra muy lejos de estar probada en las fuentes- de que la jurisprudencia clásica habría desarrollado una suerte de teoría general del contrato fundada en el consensus ${ }^{62}$. Sin embargo, si nos atenemos estrictamente al testimonio de las fuentes jurídicas romanas, estas dan cuenta más bien de la tesis contraria, vale decir, de que los clásicos nunca habrían llegado a formarse una idea unitaria de contractus $^{6} 3$, circunstancia que complica considerablemente la interpretación de los textos conservados. En efecto, encontramos aplicaciones de la bipartición "gayana" -por darle un nombre- de contrato y delito incluso en época tardo-clásica, en obras de carácter práctico escritas por prudentes que en caso alguno merecen ser calificados como mediocres juristas de provincia, lo que sí se suele afirmar de Gayo, acusado incluso de haber sido un "pre-posclásico"64,

59 D’Ors, A., “Re et verbis", en Moschetti (ed.), Atti del Congresso Internazionale di Diritto Romano $e$ di Storia del Diritto, Verona 27-28-29, IX, I948, III, Milano, Giuffrè, I95 I, 280 (n. 62). Sobre el problema de la voluntad del solvens en la solutio indebiti ver recientemente PiETrini, S., "Gai 3.9 I e la volontà del creditore volta a 'negotium contrahere'", Index: Quaderni camerti di studi romanistici, International survey of Roman law, t. XLIV, 20I 6, 285 ss.

60 En detalle sobre esta cuestión, y en especial sobre la relación entre mutui datio (re contrabere) y solutio indebiti (re obligari "extracontractual”), desde la perspectiva del autor, WEgmanN STOcKEBRAND, Obligatio re contracta, cit., I46 ss.

6 I Ver, por todos, Schulz, Classical Roman Law, cit., 467.

62 En este sentido ya Ricсовоno, S., "La formazione della teoria generale del contractus nel periodo della giurisprudenza classica", en Studi in onore die Pietro Bonfante nel XL anno d'insegnamento I, Milano, Giuffrè, I930, I 23 ss.

63 En opinión de SArgenti, Svolgimento dell'idea di contratto, cit., 73, ni siquiera en época justinianea.

64 Así D'Ors, Á., "Réplicas panormitanas vi. Sobre la suerte del contrato real en el derecho romano", Revista de Derecho Notarial, t. LxxxviII, I975, 7 ss. 
es decir, un precursor de ideas propias de la época de decadencia del derecho romano. Se trata, una vez más, de Paulo y Ulpiano.

Sin que pretendamos llevar a cabo una exégesis exhaustiva de las fuentes correspondientes, ya que ello excedería los límites de este trabajo, nos limitaremos a hacer presente que el Digesto contiene fragmentos de jurisprudencia clásica que dan cuenta de una aplicación de la dicotomía contrato-delito en la solución de cuestiones de orden práctico relativas a la legitimación pasiva de una acción, esto es, muy lejos de las inclinaciones didáctico-sistemáticas propias de un Schuljurist. Así, Paulo, en un fragmento - extraído del vigésimo libro de su comentario al edicto del pretor urbano- relativo a la bereditatis petitio - y cuyo contexto originario pudo ser, muy probablemente, la cuestión de la posibilidad de ejercer esta acción contra el debitor hereditarius ${ }^{65}$ que dolosamente había abandonado los bienes hereditarios ante litem contestatam (dolo desinere possidere) en el marco de las disposiciones del senadoconsulto Juvenciano ${ }^{66}$ - afirma que carece de importancia si se es deudor en virtud de contrato o de delito: Sed utrum ex delicto an ex contractu debitor sit, nibil refert... ${ }^{67}$. Es dable sostener que Paulo quiso hacer alusión a toda posible causa de obligación para afirmar el principio de que se puede ejercer la acción contra un debitor hereditarius con total independencia del motivo por el cual este haya devenido en deudor. Atendido el hecho de que no solo los poseedores de bienes de la herencia, sino también los deudores de la misma, pueden ser legitimados pasivos de la hereditatis petitio, Paulo pudo ver aquí la ocasión para tratar "de pasada" la cuestión de las causae obligationum: sin importar el origen de la obligación, el deudor hereditario se encuentra sometido a las disposiciones del senadoconsulto Juvenciano y, por ello, es legitimado pasivo de la acción de petición de herencia, cuando ha dejado los bienes hereditarios dolosamente antes de la litis contestatio. Por la forma en que ha llegado hasta nosotros, el fragmento parece estar concebido en términos suficientemente amplios como para abarcar toda posible causa de relación obligatoria, las que en el texto se reducen al contrato y el delito, como en Gai. 3,88.

65 D. 5,3,13,15 (Ulp. I 5 ad ed.).

66 Para el contexto palingenésico del fragmento véase Lenel, Palingenesia II, cit., c. Ioor ss. (nr. 3 I I ss.). Cfr. íD., Das Edictum perpetuum, cit., I 76 ss. En el vigésimo libro de su comentario al edicto, Paulo se refiere tres veces en términos explícitos a este senadoconsulto, a saber, en D. $5,3,28$ (post senatus consultum...), D. 5,3,30 (quod senatus voluit...) y D. 5,3,36,3 (verba senatus consulti...). Asimismo, en D. 5,3,22 y D. 5,3,40 el jurista habla de una oratio del emperador Adriano, lo que con toda seguridad hacía alusión al mismo senadoconsulto. Cfr. González Roldén, Y., Il senatoconsulto Q. Iulio Balbo et P. Iuventio Celso consulibus factum nella lettura di Ulpiano, Bari, Cacucci, 2008, 25, 2 I 6 ss.

67 D. 5,3,14 (Paul. 20 ad ed.). En términos generales sobre la legitimación pasiva de la acción de petición de herencia, D. 5,3,9 (Ulp. I 5 ad ed.): Regulariter definiendum est eum demum teneri petitione hereditatis, qui vel ius pro herede vel pro possessore possidet vel rem hereditariam. Véase también D. 5,4, IO (Pap. 6 quaest.); Gai. 4, I 44 . 
Igualmente con respecto a la legitimación pasiva de una acción, Ulpiano nos enseña que es posible ejercer una actio contra el hijo de familia, ya sea que esta provenga de un contrato o de un delito: Tam ex contractibus quam ex delictis in filium familias competit actio... ${ }^{68}$. El contexto originario de la fuente es, en términos generales, la legitimación pasiva (respecto de la condictio ex causa furtiva) del pater familias por el hurto (furtum) cometido por un hijo sometido a su patria potestad $^{69}$. Los hijos de familia carecen en principio de patrimonio; con la excepción -en época clásica- del peculio castrense ${ }^{70}$, todo lo que el hijo adquiere, lo hace para su pater. No obstante lo anterior, el filius familias puede contraer obligaciones civiles, lo que significa que es legitimado pasivo de acciones de la misma especie, si bien no se le puede ejecutar patrimonialmente en razón de lo precedentemente dicho ${ }^{71}$. De los delitos del hijo responde civilmente el padre, el cual en todo caso puede liberarse por medio de la noxae deditio. Aunque los detalles del contexto originario del fragmento -más allá de que se hablaba del $e x$ causa furtiva condicere- son desconocidos, lo que nos dice Ulpiano es que puede ejercerse una acción contra el hijo de familia con independencia de que este se haya obligado ex contractu o ex delicto. Al igual que Paulo en D. 5,3, I4, el discurso de Ulpiano solo cobra sentido si asumimos que este último quiso cubrir todas las posibles causas de obligación: decir que se puede ejercer una acción contra el hijo de familia por contrato o por delito es lo mismo que afirmar que este se puede obligar en virtud de un contrato o de un delito, ya que, como veíamos, actio y obligatio no son sino dos caras de la misma moneda, dos formas de expresar la misma idea ${ }^{72}$. Por lo demás, el fragmento de Ulpiano se asemeja muchísimo a un texto conservado en el Digesto que proviene del tercer libro del comentario de Gayo al edicto provincial, en el cual se nos enseña que el filius familias se puede obligar "por cualquier causa" (ex omnibus causis), del mismo modo que el pater familias, y que por este motivo es posible ejercer una acción contra aquel al igual que contra este: Filius familias ex omnibus causis tamquam pater familias obligatur et ob id agi cum eo tamquam cum patre familias potest ${ }^{73}$. La expresión ex omnibus causis obligatur no deja espacio a ambigüedades o dobles lecturas; sin lugar a dudas

D. 5, I, 57 (Ulp. 4I ad Sab.).

69 Para el contexto palingenésico del fragmento véase Lenel, Palingenesia II, cit., c. I I62 ss. (nr. 286I ss.), I I67. A este supuesto se refiere el mismo Ulpiano en D. I3,I,4 (Ulp. 4I ad ed.): $S i$ servus vel filius familias furtum commiserit, condicendum est domino id quod ad eum pervenit: in residuum noxae servum dominus dedere potest. Sobre la fuente véase por todos PIKA, W., Ex causa furtiva condicere im klassischen römischen Recht, Berlin, Duncker \& Humblot, I988, 89 ss., 96 ss.

70 Cfr. D. 42,6, I,9 (Ulp. 64 ad ed.). Sobre el límite de la condemnatio al valor del peculio véase D. 9,4,35 (Ulp. 4I ad Sab.).

7 I Ver por todos Kaser, M., Das Römische Privatrecht I, 2. ${ }^{a}$ ed., München, C.H. Beck, I97 I, 343.

72 Cfr. Gai. 4,2 y D. 46,I, I6,4 (Iul. 53 dig.).

73 D. $44,7,39$ (Gai. 3 ad ed. prov.). 
hace alusión a toda posible fuente de obligación, las que en el esquema gayano se reducen al contractus y el delictum (Gai. 3,88).

\section{D. ¿Una clasificación incompleta de las causae obligationum?}

La interpretación armónica -y, sobre todo, libre de prejuicios dogmatizantes- de los textos comentados nos conduce, pues, a la conclusión de que las Instituciones de Gayo recogen una divisio obligationum que en caso alguno constituye una excepción en la jurisprudencia romana, ni tampoco una excesiva simplificación de las cosas con fines puramente didácticos. Por el contrario, la dicotomía contractus-delictum que encontramos en términos explícitos en Gai. 3,88, pero que, como hemos visto, halla también expresión en otros pasajes del manual gayano, es un fiel reflejo de, al menos, una corriente doctrinal entre otras, que se manifiesta todavía en época tardo-clásica, entre los siglos iI y III d.C., en fragmentos de juristas tan reputados como Paulo y Ulpiano, cuyo contenido dista mucho de obedecer a intereses meramente pedagógicos. Según estos textos, la obligatio ex contractu se enfrenta solitaria, única y exclusivamente a la obligatio ex delicto. Es por todo lo anterior que von Lübtow afirma acertadamente que para los clásicos -esto es, no solo para Gayo- el contrato representaba más bien la relación obligatoria no delictual (nichtdeliktisches Obligationsverbältnis), el acto negocial vinculante (rechtsgeschäftlicher Bindungsakt)74. En el mismo sentido, KasER sostiene que contrato, para los romanos, habría sido todo acto lícito que genera una obligación sin más (literalmente, que da lugar a responsabilidad: jeder erlaubter baftungsbegründender Vorgang) ${ }^{75}$.

El carácter incompleto que, desde la perspectiva del dogmático moderno, se aprecia en Gai. 3,88, no significa de ninguna manera que Gayo no haya visto en su summa divisio obligationum una clasificación exhaustiva de las causas de obligación ${ }^{7}$. Por el contrario, el jurista expresa clara y concisamente que "toda obligación" nace ya sea de un contrato o de un delito; repite la misma idea desde

74 Von Lüвтоw, U., Beiträge zur Lehre von der Condictio nach römischem und geltendem Recht, Berlin, Duncker \& Humblot, I952, 99.

75 Kaser, Das Römische Privatrecht, cit., 523.

76 Sobre la pretensión de exhaustividad de Gayo véase D. I,2, I (Gai. I ad leg. xII Tab.): in omnibus rebus animadverto id perfectum esse, quod ex omnibus suis partibus constaret. Cfr. Biscard, A., "Postille gaiane", en Gaio nel suo tempo. Atti del simposio romanistico, Napoli, Jovene, I966, 2 I; Paricio, Sull'idea di contratto in Gaio, cit., i 53. En contra Talamanca, M., "Contratto e patto nel diritto romano", en Burdese (ed.), Le dottrine del contratto nella giurisprudenza romana, Padova, Cedam, 2006, 52, quien habla de una "portata apparentemente esaustiva della bipartizione"; en el mismo sentido Zimmermann, The Law of Obligations, cit., I4. Harke, Römisches Recht, cit., 40, habla de un "error evidente" ("augenfälliger Mangel"). En términos similares, Cannata, Materiali II, cit., 83, opina que la summa divisio de Gai. 3,88 solo tendría un objetivo ordenador (" $h a$ scopo puramente ordinatorio") y que, en todo caso, sería insuficiente ("anche insufficiente rispetto al suo stesso scopo"), en la medida que pasaría por alto el análisis de la estructura de los actos generadores de obligaciones. 
el punto de vista de las acciones personales en Gai. 4,2, y aplica la bipartición contractus-delictum consecuentemente, en los pasajes de sus Instituciones a los que nos hemos referido más arriba.

Asimismo, cabe hacer presente que nos parece excesivo interpretar la expresión sufficit consensisse contenida en Gai. $3,13^{6}{ }^{[77]}$ en el sentido de que toda obligación contractual estaría fundada en el consentimiento de las partes, aunque alguien pudiera sentirse tentado a hacerlo ${ }^{78}$. Mediante la frase sed sufficit eos, qui negotium gerunt, consensisse, Gayo pretendió dejar en claro la suficiencia del consenso y, consiguientemente, la irrelevancia de otros requisitos (neque verborum neque scripturae ulla proprietas desideratur), para hacer nacer una obligatio consensu contracta (categoría limitada a la compraventa, el arrendamiento, la sociedad y el mandato ${ }^{79}$. Es en este contexto específico que Gayo expone dicho principio, no habiendo en la fuente indicio alguno de que el jurista haya querido extenderlo a otras clases de contratos, de modo tal que no cabe extraer conclusiones generales sobre el consensus como fundamento de todas las obligationes ex contractu ${ }^{80}$.

Para Gayo, como para toda la jurisprudencia clásica, las obligaciones contractuales nacen de la ejecución de los actos constitutivos de los elementos esenciales de un nomen contractus (transferencia del dominio de bienes fungibles para la obligatio re contracta; promesa formal verbal, es decir, stipulatio, en la verbis contracta; anotación de una suma de dinero en el libro de cuentas del acreedor con consentimiento del deudor respecto de la litteris contracta; o el mero consentimiento en las especies de obligatio consensu contracta $)^{81}$. Es decir, solo ciertas relaciones obligatorias son susceptibles de ostentar un proprium nomen contractus $^{82}, \mathrm{y}$

77 Gai. 3,I36: Ideo autem istis modis consensu dicimus obligationes contrabi, quod neque uerborum neque scripturae ulla proprietas desideratur, sed sufficit eos, qui negotium gerunt, consensisse. unde inter absentes quoque talia negotia contrabuntur, ueluti per epistulam aut per internuntium, cum alioquin uerborum obligatio inter absentes fieri non possit.

78 Creo que plantea correctamente la cuestión SARgenti, Svolgimento dell'idea di contratto, cit., 55: "Ed è, senza dubbio, arbitrario, frutto dell'aprioristica convinzione che il consensualismo sia già radicato da tempo nel pensiero giuridico romano come principio ispiratore dell'idea di contratto, immaginare che Gaio abbia inteso la categoria in senso consensualistico, abbia visto, cioè, il consenso come elemento comune delle diverse figure di obbligazione che dovrebbero rientrare nella categoria delle obligationes ex contractu”.

79 Gai. 3, I35.

80 Cfr. Sargenti, Svolgimento dell'idea di contratto, cit., 56; Martini, Il mito del consenso, cit., 99 (n. Io); Paricio, Sull'idea di contratto in Gaio, cit., I 54; íD., Contrato, cit., 2.

8 I Gai. 3,89: Et prius videamus de his, quae ex contractu nascuntur. Harum autem quattuor genera sunt: aut enim re contrabitur obligatio aut verbis aut litteris aut consensu.

82 Así Ulpiano en D. 2,I 4,7,I (Ulp. 4 ad ed.): Quae pariunt actiones, in suo nomine non stant, sed transeunt in proprium nomen contractus: ut emptio venditio, locatio conductio, societas, commodatum, depositum et ceteri similes contractus. Para el concepto nomen contractus véase también D. I9,3, I pr. (Ulp. 32 ad ed.); D. I9,4,I,2 (Paul. 32 ad ed.); D. I9,5, I pr. (Pap. 8 quaest.); D. I9,5,3 (Iul. I4 dig.). 
ello ocurre cuando se configuran los supuestos típicos previstos por el ius civile ${ }^{8}$. De lo contrario, se permanecerá en el ámbito de los meros pactos, no protegidos por una acción, sino solo por una excepción, conforme a la regla ex nudo pacto actio non nascitur ${ }^{84}$.

En este orden de cosas, cada género de obligatio ex contractu (real, verbal, literal o consensual) tiene un fundamento distinto e independiente, de modo que entre sí no pueden remontarse a una causa matriz, común a todos. Si el tratamiento de las obligaciones contractuales (re, verbis, litteris y consensu contrahere) como cuatro géneros distintos en Gai. 3,89 (...harum autem quattuor genera sunt) no bastara para entender esta estructura dialéctica, Gayo se preocupa de recordarla a propósito de los delitos (el otro elemento de nuestra summa divisio) en Gai. $3, \mathrm{I}_{82}{ }^{[85]}$ : aquí, el jurista distingue entre los hechos ilícitos, los cuales forman parte de un mismo género (uno gerere consistit obligatio), y los contratos, que consisten en cuatro géneros independientes (in IIII genera diducantur). La misma estructura dialéctica se aprecia en las res cottidianae: según esta fuente, los delitos conforman un mismo género (omnia unius generis sunt), es decir, tienen un fundamento jurídico unitario; en cambio (alioquin), los contratos no "consisten" solamente en una cosa ( $r e$ ), sino también en las palabras (verbis) o el consentimiento (consensu) ${ }^{86}$. Recién en el derecho justinianeo, en el cual se asienta una idea de contractus fundada en la conventio, las obligationes re, verbis, litteris y consensu contractae ya no serán tratadas como géneros independientes, sino como especies de un mismo género: el contrato-convención ${ }^{8}$.

De lo dicho es posible concluir que dentro del esquema gayano de las causae obligationum cada vínculo contractual representa, en definitiva, un fenómeno distinto, un género en sí mismo, a diferencia de los delitos, que tienen un fun-

83 Sobre la tipicidad contractual en el derecho romano véase por todos Betri, E., "Der Typenzwang bei den römischen Rechtsgeschäften und die sogenannte Typenfreiheit des heutigen Rechts", en Festscbrift für Leopold Wenger I, München, C.H. Beck, I 944, 249 ss.; Talamanca, M., "La tipicità dei contratti romani fra 'conventio' e 'stipulatio' fino a Labeone”, en Mrlazzo (ed.), Contractus e pactum. Tipicità e libertà negoziale nell'esperienza tardo-repubblicana, Napoli, Edizioni Scientifiche Italiane, I990, 35 ss.

84 D. 2,I $4,7,4$ (Ulp. 4 ad ed.); PS 2, I 4, I.

85 Gai. 3,182: Transeamus nunc ad obligationes, quae ex delicto nascuntur, ueluti si quis furtum fecerit, bona rapuerit, damnum dederit, iniuriam commiserit, quarum omnium rerum uno genere consistit obligatio, cum ex contractu obligationes in IIII genera diducantur, sicut supra exposuimus.

86 D. 44,7,4 (Gai. 3 res cott.): Ex maleficio nascuntur obligationes, veluti ex furto, ex damno, ex rapina, ex iniuria. quae omnia unius generis sunt: nam bae re tantum consistunt, id est ipso maleficio, cum alioquin ex contractu obligationes non tantum re consistant, sed etiam verbis et consensu. Como es sabido, en las res cottidianae no hay referencia alguna al litteris contrabere.

87 I. 3,I3,2: (...) Prius est, ut de bis quae ex contractu sunt dispiciamus. Harum aeque quattuor species sunt: aut enim re contrabuntur aut verbis aut litteris aut consensu. de quibus singulis dispiciamus. Cfr. PT 3,I3,2 para la identificación bizantina entre contrato y convención, derivada de la noción ulpianea de pacto contenida en D. 2,I 4,I,2 (Ulp. 4 ad ed.): Et est pactio duorum pluriumve in idem placitum et consensus. 
damento común ${ }^{88}$. Lo anterior avala, pues, lo que venimos diciendo: la noción de contrato que se aprecia en las Instituciones de Gayo no tiene como base unificadora un elemento convencional, el acuerdo de voluntades de las partes. La insuficiencia -insisto: según nuestros actuales criterios dogmáticos- de la dicotomía contrato-delito no puede ser atribuida tout court al orden de materias de las Instituciones de Gayo en particular, ni a la experiencia jurídica romana en general, sin violentar con ello el genuino sentido de las fuentes que tenemos a disposición.

\section{Conclusiones y perspectivas}

Como hemos visto, en Gai. 3,88 ss. se expone la estructura de diversas relaciones jurídicas, todas las cuales presentan como característica común el hecho de proceder de una causa constitutiva de un contractus. De acuerdo al orden de materias contenido en las Instituciones de Gayo, los supuestos de contrabere no encuentran su fundamento unitario en el consensus: cada genus de obligación contractual nace de una actividad humana concreta, lícita y tipificada, que tiene la virtud, reconocida por el ordenamiento jurídico, de desencadenar una relación obligatoria ex iure civili, sin que para ello sea esencial que se configure un acuerdo de voluntades entre las partes. Así, Gayo no tiene problemas en tratar como contratos figuras en que evidentemente falta una conventio, como es el caso de la tutela, la dote y la gestión de negocios ajenos. Asimismo, el jurista es consistente al aplicar la bipartición contractus-delictum incluso respecto de la solutio indebiti. De lo contrario, no habría planteado sus reservas respecto del carácter contractual del pago de lo no debido, inmediatamente después de afirmar que de esta figura nace una obligación "por la cosa" (re) al igual que de la dación en mutuo. El elemento que se echa de menos para configurar este supuesto como contractual no es la ausencia de un acuerdo de voluntades, respecto del cual no se dice una sola palabra, sino la falta de intención de vincularse, ya que quien ejecuta por error una prestación de dar que cree existente, más bien quiere extinguir una obligación que hacerla nacer, y el contrato para Gayo no es otra cosa que un acto lícito que engendra obligaciones.

En síntesis: para Gayo y parte de la jurisprudencia clásica -como Paulo y Ulpiano-, para que nazca una relación obligatoria ex contractu es suficiente que el hecho del que ella procede no sea ilícito (ex delicto). La identificación del contrato con la convención es ya otra historia.

88 En este sentido ya Orestano, Obligationes e dialettica, cit., 455 ss.; recientemente Harke, J. D., Studien zu Vertrag und Eigentumserwerb im römischen Recht, Berlin, Duncker \& Humblot, 20I3, 38 , quien plantea la existencia de tres "sistemas contractuales" en derecho romano, uno para cada género: contratos reales, verbales y consensuales. 


\section{Bibliografía}

Avenarius, M., Der pseudo-ulpianische liber singularis regularum. Entstebung, Eigenart und Überlieferung einer hochklassischen Furistenschrift, Göttingen, Wallstein, 2005 .

Avenarius, M., “Tradition, Vorverständnis und Wirkungsgeschichte der Quellen. Vom Einfluß der geisteswissenschaftlichen Hermeneutik auf das romanistische Verstehen”, en íD. (ed.), Hermeneutik der Quellentexte des Römischen Rechts, Baden-Baden, Nomos, 2008, 9 ss.

Baldus, C., "Zum Begriff des debitum bei Cervidius Scaevola. Schuldrecht, Erbrecht und Prozessrecht zwischen Hochklassik und Spätklassik", en Harke (ed.), Facetten des römischen Erbrechts, Berlin/Heidelberg, Springer, 20 I 2, I ss.

Behrends, O., Die Wissenschaftslebre im Zivilrecht des Q. Mucius Scaevola pontifex, en Nachrichten der Akademie der Wissenschaften in Göttingen I. Philologisch-bistorische Klasse Nr. 7, Göttingen, Vandenhoeck \& Ruprecht, I976.

Beтti, E., "Der Typenzwang bei den römischen Rechtsgeschäften und die sogenannte Typenfreiheit des heutigen Rechts", en Festschrift für Leopold Wenger I, München, C.H. Beck, I 944, 249 ss.

Biscardi, A., "Postille gaiane", en Gaio nel suo tempo. Atti del simposio romanistico, Napoli, Jovene, I966, I 5 ss.

Bretone, M., Tecniche e ideologie dei giuristi romani, 2. ${ }^{\text {a }}$ ed., Napoli, Edizioni Scientifiche Italiane, I982.

Brutti, M., "Storiografia e critica del sistema pandettistico", Quaderni fiorentini per la storia del pensiero giuridico moderno, t. viII, I979, 3 I 7 ss.

Brutti, M., "Gaio e il ius controversum”, Annali del Seminario Giuridico della Università di Palermo, t. LV, 201 2, 75 ss.

Cannata, C. A., “Sulla 'divisio obligationum' nel diritto romano repubblicano e classico", Iura: Rivista internazionale di diritto romano e antico, t. xxI, I970, 52 ss.

Cannata, C. A., Materiali per un corso di fondamenti del diritto europeo II, Torino, Giappichelli, 2008. 
Cenderelli, A., La negotiorum gestio. Corso esegetico di diritto romano I. Struttura, origini, azioni, Torino, Giappichelli, I997.

Cuena Boy, F., Sistema jurídico y derecho romano. La idea de sistema jurídico y su proyección en la experiencia jurídica romana, Santander, Universidad de Cantabria, I 998.

De los Mozos Touya, J. J., "La clasificación de las fuentes de las obligaciones en las Instituciones de Gayo y de Justiniano y su valor sistemático en el moderno derecho civil", Seminarios Complutenses de Derecho Romano, t. vi, I994, IO3 Ss.

D’Ors, A., “Re et verbis”, en Moschetti (ed.), Atti del Congresso Internazionale di Diritto Romano e di Storia del Diritto, Verona 27-28-29, Ix, I 948 III, Milano, Giuffrè, I95 I, 265 ss.

D’Ors, A., "Réplicas panormitanas vi. Sobre la suerte del contrato real en el derecho romano", Revista de Derecho Notarial, t. LxxxviII, I975, 7 ss.

Falcone, G., Obligatio est iuris vinculum, Torino, Giappichelli, 2003.

Falcone, G., "Sistematiche gaiane e definizione di obligatio", en CapogrossiColognesi/Cursi (eds.), Obligatio-obbligazione. Un confronto interdisciplinare (Atti del Convegno di Roma 23-24 settembre 2010), Napoli, Jovene, 20 I I, I 7 ss.

FinazzI, G., Ricerche in tema di negotiorum gestio II.I. Requisiti delle actiones negotiorum gestorum, Napoli, Jovene, 2003.

Flume, W., "Die Bewertung der Institutionen des Gaius", Zeitschrift der Savigny Stiftung für Rechtsgeschichte, romanistische Abteilung, t. LxxIx, I962, I ss.

Fuhrmann, M., Das systematische Lebrbuch. Ein Beitrag zur Geschichte der Wissenschaften in der Antike, Göttingen, Vandenhoeck \& Ruprecht, I960.

Garofalo, L., "Contratto, obbligazione e convenzione in Sesto Pedio”, en BurDESE (ed.), Le dottrine del contratto nella giurisprudenza romana, Padova, Cedam, 2006, 337 ss.

Giaro, T., "Über methodologische Werkmittel der Romanistik", Zeitschrift der Savigny Stiftung für Rechtsgeschichte, romanistische Abteilung, t. cv, I988, I80 ss. 
González Roldán, Y., Il senatoconsulto Q. Iulio Balbo et P. Iuventio Celso consulibus factum nella lettura di Ulpiano, Bari, Cacucci, 2008.

Gordley, J., The Philosophical Origins of Modern Contract Doctrine, Oxford, Oxford University Press, I99I.

Grosso, G., Il sistema romano dei contratti, 3. . ed., Torino, Giappichelli, I963.

Guzmán Brito, A., "Dialéctica, casuística y sistemática en la jurisprudencia romana", Revista de Estudios Histórico-furídicos, t. v, I980, I 7 ss.

Guzmán Brito, A., Las cosas incorporales en la doctrina y en el derecho positivo, 2. a ed., Santiago, Editorial Jurídica de Chile, 2006.

Guzmán Brito, A., "El carácter dialéctico del sistema de las Institutiones de Gayo", en Carvajal (ed.), Estudios de derecho romano en homenaje al Prof. Dr. D. Francisco Samper, Santiago, Librotecnia, 2007, 427 ss.

Guzmán Brito, A., “La tripartición del 'omne ius' en 'personae res actiones' y la doctrina retórica de las 'circumstantiae", en Fides Humanitas Ius. Studii in onore di Luigi Labruna, Iv, Napoli, Edizioni Scientifiche Italiane, 2007, 2429 ss.

Harke, J. D., Geschäftsfübrung und Bereicherung, Berlin, Duncker \& Humblot, 2007.

Harke, J. D., Studien zu Vertrag und Eigentumserwerb im römischen Recht, Berlin, Duncker \& Humblot, 2013.

Harke, J. D., Römisches Recht. Von der klassischen Zeit bis zu den modernen Kodifikationen, 2. ${ }^{a}$ ed., München, C.H. Beck, 20 г6.

Hoetink, H. R., "Über anachronistische Begriffsbildung in der Rechtsgeschichte”, Zeitschrift der Savigny Stiftung für Rechtsgeschichte, romanistische Abteilung, t. LXXII, I955, 39 ss.

Hoffmann, H.-J., Die Abstufung der Fabrlässigkeit in der Rechtsgeschichte. Unter besonderer Berücksichtigung der culpa levissima, Berlin, Walter de Gruyter, I 968.

Kaser, M., "Gaius und die Klassiker", en Zeitschrift der Savigny Stiftung für Rechtsgeschichte, romanistische Abteilung, t. Lxx, I953, I 27 ss. 
Kaser, M., "La classicità di Gaio", en Gaio nel suo tempo. Atti del simposio romanistico, Napoli, Jovene, I966, 42 ss.

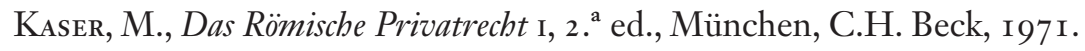

Kaser, M., “Divisio obligationum”, en Stern/Lewis (eds.), Studies in Fustinian's Institutes in memory of 7.A.C. Thomas, London, Sweet \& Maxwell, I983, 73 ss.

Kaser, M./Knütel, R., Römisches Privatrecht, $20^{\mathrm{a}}$ ed., München, C.H. Beck, 20 I 4.

Kegel, G., Vertrag und Delikt, München, Heymanns, 2002.

Kollmann, A., Begriffs- und Problemgeschichte des Verbältnisses von formellem und materiellem Recht, Berlin, Duncker \& Humblot, 1996.

KRÜGER, P., Geschichte der Quellen und Litteratur des römischen Rechts, 2. ${ }^{\text {a }}$ ed., München/Leipzig, Duncker \& Humblot, I9 2.

Laborenz, M., Solutio als causa. Die Frage des Abstraktionsprinzips im römischen Recht, Köln/Weimar/Wien, Böhlau, 20 I4.

La Pira, G., "La genesi del sistema nella giurisprudenza romana. L'arte sistematrice", Bullettino dell'Istituto di Diritto Romano 'Vittorio Scialoja', t. XLII, I934, 336 ss.

LA Pira, G., "La genesi del sistema nella giurisprudenza romana. Il metodo", en Studia et Documenta Historiae et Iuris, t. I, I935, 3 I 9 ss.

La Pira, G., "La genesi del sistema nella giurisprudenza romana. Il concetto di scienza e gli strumenti della costruzione scientifica", Bullettino dell'Istituto di Diritto Romano 'Vittorio Scialoja', t. XLIV, I936, I3 I ss.

Lauria, M., "Contractus, delictum, obligatio (a proposito di recenti studi)”, en Studia et Documenta Historiae et Iuris, t. IV, I938, I63 ss.

Lenel, O., Palingenesia iuris civilis I-II, Leipzig, Bernhard Tauschnitz, I889.

Lenel, O., Das Edictum perpetuum. Ein Versuch zu seiner Wiederherstellung, 3. ${ }^{a}$ ed., Leipzig, Bernhard Tauschnitz, I927.

Liebs, D., "Jurisprudenz", en Sallmann (ed.), Die Literatur des Umbruchs. Von der römischen zur christlichen Literatur. II7 bis 284 n. Chr., en Herzog/ 
Schmidt (eds.), Handbuch der lateinischen Literatur der Antike Iv, München, C.H. Beck, I 997, 83 ss.

Lombardi, L., Saggio sul diritto giurisprudenziale, Milano, Giuffrè, I967.

Martini, R., “Genus e species nel linguaggio gaiano”, en Synteleia Vincenzo Arangio-Ruiz I, Napoli, Jovene, I964, 462 ss.

Martini, R., "Il mito del consenso nella dottrina del contratto", Iura: Rivista internazionale di diritto romano e antico, t. XLII, I99I, 97 ss.

Martini, R., "La sistematica dei giuristi romani", Index: Quaderni camerti di studi romanistici, International survey of Roman law, t. XxxIv, 2006, 87 ss.

Martini, R., "Gaio e le res cottidianae", Annali del Seminario Giuridico della Università di Palermo, t. Lv, $20 \mathrm{I} 2, \mathrm{I} 73$ ss.

Mattioli, F., "Un tentativo di messa a punto riguardo alla più recente dottrina sui Tituli ex corpore Ulpiani. Ipotesi e prospettive di ricerca”, en Purpura (ed.), Revisione ed integrazione dei Fontes Iuris Romani Anteiustiniani (FIRA). Studi preparatori II. Auctores - negotia, Torino, Giappichelli, 20 I 2, 85 ss.

Mayer-Maly, T., "Divisio obligationum”, en The Irish Furist, t. II, I967, 375 ss.

Mercogliano, F., 'Tituli ex corpore Ulpiani'. Storia di un testo, Napoli, Jovene, I997.

Nanz, K.-P., Die Entstehung des allgemeinen Vertragsbegriffs im I 6. bis I 8. Jahrbundert, München, Schweitzer, I985.

Nelson, H. L. W., Überlieferung, Aufbau und Stil von Gai Institutiones, Leiden, Brill, I98I.

Nelson, H. L. W./Manthe, U., Gai Institutiones III 88-I8I. Die Kontraktsobligationen. Text und Kommentar, Berlin, Duncker \& Humblot, I999.

Nörr, D., Divisio und partitio. Bemerkungen zur römischen Rechtsquellenlebre und zur antiken Wissenschaftstheorie, Berlin, Schweitzer, I972.

Nörr, D., "Zur Interdependenz von Prozeßrecht und materiellem Recht am Beispiel der lex Aquilia", en Chiusi/Kaiser/Spengler (eds.), Historiae iuris antiqui III, Goldbach, Keip, 2003, I 727 ss. 
Nörr, K. W., "Das römische Recht zwischen Technik und Substanz: Bemerkungen zu seiner Rolle am Ende des 20. Jahrhunderts", Zeitschrift für Europäisches Privatrecht, t. II, I994, 67 ss.

Orestano, R., "Obligationes e dialettica”, en Droits de l'antiquité et sociologie juridique. Mélanges Henri Lévy-Brubl, Paris, Sirey, I959, 445 ss.

Orestano, R., Introduzione allo studio del diritto romano, Bologna, Il Mulino, I987.

Paricio, J., "Las fuentes de las obligaciones en la tradición gayano-justinianea", en íD. (ed.), Derecho romano de obligaciones. Homenaje al profesor Fosé Luis Murga Gener, Madrid, Centro de Estudios Ramón Areces, I994, 49 ss.

Paricio, J., "Sull'idea di contratto in Gaio", en VAcca (ed.), Causa e contratto nella prospettiva storico-comparatistica, Torino, Giappichelli, I997, I 5 I ss.

Paricio, J., Contrato. La formación de un concepto, Cizur Menor, Civitas, 2008.

Pernice, A., "Parerga III. Zur Vertragslehre der römischen Juristen”, Zeitschrift der Savigny Stiftung für Rechtsgeschichte, romanistische Abteilung, t. Ix, I888, I 95 ss.

Pietrini, S., "Gai 3.9 I e la volontà del creditore volta a "negotium contrahere", en Index: Quaderni camerti di studi romanistici, International survey of Roman law, t. XLIV, 20I6, 285 ss.

PıкA, Wolfram, Ex causa furtiva condicere im klassischen römischen Recht, Berlin, Duncker \& Humblot, I988.

Ricсовоno, S., "La formazione della teoria generale del contractus nel periodo della giurisprudenza classica”, en Studi in onore di Pietro Bonfante nel XL anno d'insegnamento I, Milano, Giuffrè, I930, I 23 ss.

SANTUCCI, G., "Utilitas contrahentium. Note minime su una regula che 'cacciata dalla porta rientrò dalla finestra", en FIORI (ed.), Modelli teorici e metodologici nella storia del diritto privato 3, Napoli, Jovene, 2008, 277 ss.

SARgenti, M., "La sistematica pregaiana delle obbligazioni e la nascita dell'idea di contratto", en Bona/Gallo/Goria/Lantella/íd./Scapini/Zannini (eds.), Prospettive sistematiche nel diritto romano, Torino, Giappichelli, I976, 455 ss. 
Sargenti, M., "Svolgimento dell'idea di contratto nel pensiero giuridico romano", en Iura: Rivista internazionale di diritto romano e antico, t. xxxIx, I988, 24 Ss.

Scarano Ussani, V., L'ars dei giuristi. Considerazioni sullo statuto epistemologico della giurisprudenza romana, Torino, Giappichelli, I997.

Schiavone, A., Giuristi e nobili nella Roma repubblicana. Il secolo della rivoluzione scientifica nel pensiero giuridico antico, Roma/Bari, Laterza, I 992.

SchröDer, J., Recht als Wissenschaft. Geschichte der juristischen Methodenlebre in der

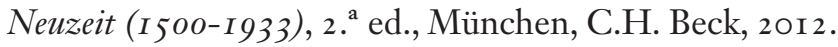

Schulz, F., Classical Roman Law, Oxford, Oxford University Press, I95 I.

Schulz, F., Geschichte der römischen Rechtswissenschaft, Weimar, Hermann Böhlaus Nachfolger, I96r.

SEgrè, G., "Sulla classificazione delle cause delle obligationes nelle Istituzioni di Gaio", Rendiconti della Reale Accademia Nazionale dei Lincei v, serie vi, fasc. 3-4, 49 ss. = Scritti vari di diritto romano, Torino, Giappichelli, I952, 433 ss.

SEILER, H. H., Der Tatbestand der negotiorum gestio im römischen Recht, Köln/Graz, Böhlau, I968.

Stagl, J. F., "Das didaktische System des Gaius", Zeitschrift der Savigny Stiftung für Rechtsgeschichte, romanistische Abteilung, t. cxxxI, 20 I4, 3 I 3 ss.

STEIN, P., “The Development of the Institutional System”, en íD./LEwis (eds.), Studies in Justinian's Institutes in memory of 7.A.C. Thomas, London, Sweet \& Maxwell, i983, I 5 I ss.

Stolfi, E., "Die Juristenausbildung in der römischen Republik und im Prinzipat", en Baldus/Finkenauer/RüfNer (eds.), Juristenausbildung in Europa zwischen Tradition und Reform, Tübingen, Mohr Siebeck, 2008, 9 ss.

Talamanca, M., "Lo schema 'genus-species' nelle sistematiche dei giuristi romani”, en La filosofia greca e il diritto romano (colloquio italo-francese) II, Roma, Accademia Nazionale dei Lincei, I977.

Talamanca, M., “Obbligazioni (diritto romano)", Enciclopedia del Diritto, t. xxIx, Milano, Giuffrè, ı979, I ss. 
Talamanca, M., “La tipicità dei contratti romani fra 'conventio' e 'stipulatio' fino a Labeone", en Milazzo (ed.), Contractus e pactum. Tipicità e libertà negoziale nell'esperienza tardo-repubblicana, Napoli, Edizioni Scientifiche Italiane, I990, 35 ss.

Talamanca, M., "Contratto e patto nel diritto romano", en Burdese (ed.), Le dottrine del contratto nella giurisprudenza romana, Padova, Cedam, 2006, 37 ss.

VAcca, L., Metodo casistico e sistema prudenziale, Padova, Cedam, 2006.

Varvaro, M., "La dote, il ius singulare e il sistema didattico di Gaio", Seminarios Complutenses de Derecho Romano, t. XxIx, 2016, 409 ss.

Villey, M., Recherches sur la litterature didactique du droit romain. A propos d'un texte de Ciceron, De oratore I-I 88 à I 90 , Paris, Domat-Montchrestien, I 945.

Vincenti, U., Categorie del diritto romano, Napoli, Jovene, 2007.

Voci, P., La dottrina romana del contratto, Milano, Giuffrè, I946.

Volante, R., Il sistema contrattuale del diritto comune classico. Struttura dei patti e individuazione del tipo. Glossatori e ultramontani, Milano, Giuffrè, 200 I.

voN Lüвтоw, U., "Betrachtungen zum gajanischen Obligationenschema", en Moschetri (ed.), Atti del Congresso Internazionale di Diritto Romano e di Storia del Diritto, Verona 27-28-29, IX, I948, III, Milano, Giuffrè, I95 I, 239 ss.

Von Lüвтоw, U., Beiträge zur Lehre von der Condictio nach römischem und geltendem Recht, Berlin, Duncker \& Humblot, 1952.

Wegmann Stockebrand, A., Obligatio re contracta. Ein Beitrag zur sogenannten Kategorie der Realverträge im römischen Recht, Tübingen, Mohr Siebeck, 20 I 7.

Wieacker, F., "Griechische Wurzeln des Institutionensystems", Zeitschrift der Savigny Stiftung für Rechtsgeschichte, romanistische Abteilung, t. Lxx, I953, 93 ss.

Wieacker, F., "Über das Verhältnis der römischen Fachjurisprudenz zur griechisch-hellenistischen Theorie", Iura: Rivista internazionale di diritto romano e antico, t. $\mathrm{xx}, \mathrm{I} 969,448$ ss. 
Wieacker, F., "Grundlagen der Systembildung in der römischen Jurisprudenz”, en Buccellato (ed.), La sistematica giuridica. Storia, teoria e problemi attuali, Roma, Istituto della Enciclopedia Italiana, I991, 63 ss.

Woøodkiewicz, W., Les origines romaines de la systématique du droit civil contemporain, Wrocław/Warszawa/Kraków/Gdańsk, Zakład Narodowy Imienia Ossolińskich Wydawnictwo Polskiej Akad. Nauk, 1978.

Wunner, S. E., Contractus. Sein Wortgebrauch und Willensgebalt im klassischen römischen Recht, Köln/Graz, Böhlau, I964.

Zimmermann, R., The Law of Obligations. Roman Foundations of the Civilian Tradition, Cape Town, Oxford University Press, I992; reimp. Oxford, I996. 